\title{
Development of OTM Syngas Process and Testing of Syngas-Derived Ultra-clean Fuels in Diesel Engines and Fuel Cells
}

\author{
Budget Period 1
}

\section{Topical Report}

For Reporting Period Starting January 1, 2001 and Ending October 31, 2001

Principal Authors:

E.T. (Skip) Robinson, Principal Investigator

James P. Meagher, Program Administrator

Ravi Prasad, Corporate Fellow

Report Issue Date: October 2001

\section{DOE Cooperative Agreement No. DE-FC26-01NT41096}

Submitting Organizations:

Primary: $\quad$ Praxair, Inc.

P.O. Box 44

175 East Park Drive

Tonawanda, NY 14150

Subcontractors: BP Amoco

Torix, Inc.

150 W. Warrenville Road

7165 Hart St., Suite B

Mail Code $\mathrm{H}-5$

Mentor, OH 44060

Naperville, IL 60566

International Truck and Engine Corp. Nuvera Fuel Cells

10400 W. North Avenue

15 Acorn Park

Melrose Park, IL 60160

Cambridge, MA 02140 


\section{DISCLAIMER}

This report was prepared as an account of work sponsored by an agency of the United States Government. Neither the United States Government nor any agency thereof, nor any of their employees, makes any warranty, express or implied, or assumes any legal liability or responsibility for the accuracy, completeness, or usefulness of any information, apparatus, product, or process disclosed, or represents that its use would not infringe privately owned rights. Reference herein to any specific commercial product, process, or service by trade name, trademark, manufacturer, or otherwise does not necessarily constitute or imply its endorsement, recommendation, or favoring by the United States Government or any agency thereof. The views and opinions of authors expressed herein do not necessarily state or reflect those of the United States Government or any agency thereof.
ABSTRACT through September 15, 2001 in the following task areas:
- Task 1 Materials Development
- Task 2 Composite Element Development
- Task 3 Tube Fabrication
- Task 4 Reactor Design and Process Optimization
- Task 5 Catalyst Development
- Task 6 P-1 Operation
- Task 8 Fuels and Engine Testing
- Task 10 Project Management

This topical report summarizes work accomplished for the Program from January 1

OTM benchmark material, LCM1, exceeds the commercial oxygen flux target and was determined to be sufficiently robust to carry on process development activities. Work will continue on second-generation OTM materials that will satisfy commercial life targets.

Three fabrication techniques for composite elements were determined to be technically feasible. These techniques will be studied and a lead manufacturing process for both small and large-scale elements will be selected in the next Budget Period.

Experiments in six P-0 reactors, the long tube tester (LTT) and the P-1 pilot plant were conducted. Significant progress in process optimization was made through both the experimental program and modeling studies of alternate reactor designs and process configurations.. Three tailored catalyst candidates for use in OTM process reactors were identified.

Fuels for the International diesel engine and Nuvera fuel cell tests were ordered and delivered. Fuels testing and engine development work is now underway. 


\section{Development of OTM Syngas Process and Testing of Syngas-Derived Ultra-clean Fuels in Diesel Engines and Fuel Cells \\ Budget Period 1}

\section{TABLE OF CONTENTS}

1.0 Executive Summary

$\frac{\text { Page }}{4}$

2.0 Introduction

3.0 Results by Task

3.1 Task 1: Materials Development 7

3.2 Task 2: Composite Element Development 12

3.3 Task 3: Tube Fabrication 15

3.4 Task 4: Reactor Design and Process Optimization 17

3.5 Task 5: Catalyst Development 26

3.6 Task 6: P-1 Operation 29

3.7 Task 7: P-2 Build and Operation 31

3.8 Task 8: Fuel and Engine Testing 31

3.9 Task 9: Market Study 34

3.10 Task 10: Program Management 34

4.0 Conclusion 35

$\begin{array}{lll}5.0 & \text { References } & 37\end{array}$

6.0 Appendices

6.1 Disk Reactor A-1

6.2 P-0 Reactor A-2

6.3 Long Tube Tester A-3

6.4 P-1 Pilot Plant A-4

6.5 Element Manufacturing Facility A-5

$\begin{array}{lll}6.6 & \text { Nuvera MPR Facility A-7 }\end{array}$

6.7 International Truck and Engine Facility A-8 
$\underline{\text { List of Tables }}$

$\underline{\text { Page }}$

Table 1. Thermal Expansion Coefficients of Lead Material Candidates 10

Table 2. $\quad$ Vickers Indentation Method Measurements 12

Table 3. $\quad$ Single Cylinder Engine Specifications 32

Table 4. $\quad$ MPR Test Matrix 33

Table 5. Fuel Cell Test Matrix 33

\section{List of Figures}

Figure 1. Systems Approach to UCTF 6

Figure 2. $\quad$ Flux of Lead Commercial Material Candidates 8

Figure 3. $\quad$ Creep Rate of Lead Materials as a Function of T and Stress 9

Figure 4. Thermal expansion of LCM3 as a Function of Temperature $\quad 10$

Figure 5. Chemical Expansion of LCM1, LCM3 and LCM7 vs. $p \mathrm{O}_{2} \quad 11$

Figure 6. $\quad$ Flux of LCM1 and LCM2 Disks versus Substrate Thickness 14

Figure 7. $\quad$ Flux of LCM2 Disks versus Temperature 14

Figure 8. $\quad$ Schematic Diagram of P-O Reactor 19

Figure 9. Relative Leak Rates of OTM Seals after Thermal Cycling 22

Figure 10. Relative Leak Rate as a Function of Time for OTM Seals 23

Figure 11. Velocity Vectors Showing the Recirculation Zone above Lance 24

Figure 12. Temperature Contours at the Top of the OTM Tube 25

Figure 13. Comparison of Rigorous and Empirical Kinetic Model 28

Figure 14. CatA Relative Activity versus Target Activity over a Range of T 29

Figure 15. Reactor Temperature Ramp 31

Figure 16. Nuvera Fuel Cells Modular Pressurized Reactor Schematic 33

\section{$\underline{\text { List of Acronyms }}$}

A tubes Tube with a large nominal outside diameter

B tubes Tube with a small nominal outside diameter

CFD Computational Fluid Dynamics

LCM Lead Candidate Material

LTT Long Tube Tester, single tube pilot plant

OTM Oxygen Transport Membrane

P-0 Small bench scale test reactors capable of testing single OTM tubes up to 8 inches in length at elevated pressures and temperature.

P-1 Multi-tube pilot plant 


\section{Executive Summary}

This program has two primary focuses: 1) development of an advanced, low cost syngas technology based on ceramic oxygen transport membranes and 2) the evaluation of syngas derived ultra-clean fuels in Nuvera fuel cells; and the development of advanced compression ignition engines /after- treatment/ultra-clean fuel systems. Although the program had a late start, significant progress has been made in the OTM syngas tasks. The fuels and engine development (Task 8) work was initiated in August.

Task 1, Materials Development has created and fabricated a number of OTM materials that promise to deliver both the target oxygen flux and superior mechanical properties required for a long-term commercial operation. Two new materials were completely characterized. Five other materials are in various stages of fabrication or testing. All of these materials satisfy the oxygen flux requirement; several have demonstrated superior mechanical properties such as creep, fracture toughness and thermal and compositional expansion. The benchmark material, LCM1, exceeds the commercial oxygen flux target and is sufficiently robust to carry on with process development and pilot plant activities Work will continue to develop materials that satisfies commercial life targets.

Task 2, Composite Element Development has focused on optimizing element parameters such as oxygen flux and strength while developing the fabrication techniques to commercially manufacture these elements. Experiments to quantify the role of element morphology and temperature effects were completed. Three manufacturing techniques for making robust composite tubes have proven technically feasible based on the capability to make leak free composite elements with uniform geometry. The advantages and disadvantages of each technique are being studied; a decision to select the lead manufacturing process has been postponed until the next budget period, pending selection of commercial material(s) in Task 1.

Work continued on the scale-up of manufacturing techniques for producing both small and large-scale ceramic OTM elements (Task 3). A number of composite elements with inside dense films were made for P-0 tests. Large tubes (up to $140 \mathrm{~cm}$ in length) for the LTT and P-1 pilot plants were made and are being tested. These tubes incorporate a special open end for sealing and exhibit excellent straightness and roundness. Three technically viable techniques for making composite elements with inside films are under development. Final selection of the commercial manufacturing technique is pending selection of the commercial materials. However work with the current candidates LCM1 and LCM2 will enable rapid changeover to the new material when it is available.

Significant progress has been made in developing process models of the OTM reactor (Task 4). A CFD code has been developed that includes hydrodynamic descriptions of the reactor internals, and kinetic descriptions for both oxygen diffusion through the ceramic OTM and heterogeneous catalysis of steam methane reforming and water gas shift reactions. Fluid flow, heat and mass transfer and reaction kinetics are coupled to give an accurate representation of the reactor performance. The model is being validated 
against P-0, LTT and P-1 results. These models, plus simpler codes are being used to evaluate alternative reactor designs and process configurations.

Seals to hold the ceramic elements in the reactor and maintain a large pressure difference have been developed and are in use in all of the bench scale and pilot plant units. Two design types are being developed. Both types can be pressure and thermally cycled and can accommodate the thermal and compositional expansion characteristics of the OTM elements.

P-0 tests in six reactors are evaluating alternative element architectures and materials, as well as studying effect of process conditions and tube morphology on temperature profiles and element performance.

Construction of a new pilot plant, the Long Tube Tester (LTT), was completed at the end of June. This unit is capable of testing OTM elements up to $\sim$ six feet in length with a variety of process gases and flow configurations at target temperatures and pressures. Commissioning of all systems is complete and the unit is in start-up mode.

The P-1 Pilot Plant (Task 6) achieved a milestone operation of 100 hours, including successful start-up and shutdown without a tube failure. This run utilized two OTM elements. The unit is now configured with 15 OTM elements, $140 \mathrm{~cm}$ length, and is undergoing start-up.

Development of tailored catalysts (Task 5) suitable for the unique operating environment of an OTM process reactor has successfully yielded three candidates, all of which can satisfy activity targets. At least one catalyst system qualifies for the P-1 application, meeting the milestone target for this budget period. Work continues to optimize the performance, cost and life characteristics of a commercial catalyst system. A detailed model based on intrinsic kinetic experiments has been completed for one of the catalyst candidates. This model is incorporated in the reactor CFD code.

Fuels testing and engine development work (Task 8) is now underway at Nuvera Fuel Cells and International Truck and Engine. Experimental plans have been finalized and Fischer Tropsch-based fuels (an FTL naphtha for Nuvera and a FTL diesel for International) have been delivered to both sites.

Program Management (Task 10) has been successful in kicking off all sub-contractor work in a timely fashion after the DOE /Praxair contract was signed on May 21, 2001. Contracts with BP Amoco, Nuvera Fuel Cells and International Truck and Engine were completed by August and work is underway at all sites. In addition, very long lead fuel requirements were anticipated and delivered to the subcontractors in time to prevent delays in Task 8 . 


\section{Introduction}

The DOE's Office of Fossil Energy created strategic partnerships targeted at the development and verification of advanced fuel-making processes that utilize fossil feedstocks. These processes will enable the production of ultra-clean transportation fuels that improve the environment, while also expanding and diversifying the fossil resource base. In response to the DOE's solicitation for research and development leading to the production of ultra-clean transportation fuels from fossil resources, Cooperative Agreement number DE-FC26-01NT41096 for work entitled "Development of OTM Syngas Process and Testing of Syngas-Derived Ultra-clean Fuels in Diesel Engines and Fuel Cells" was awarded to Praxair.

The objectives of this project are: (1) develop an advanced syngas technology, based on Oxygen Transport Membranes (OTMs), that will provide a step change reduction in the cost of converting natural gas to a spectrum of liquid transportation fuels and thereby improve the prospects for meeting vehicle emissions targets with cost competitive ultra clean transportation fuels (UCTFs); (2) evaluate the performance of, and emissions from selected syngas-derived UCTFs in advanced vehicle propulsion systems, including advanced diesel engines with post treatment and fuel cells; and 3) develop an optimized $\mathrm{UCTF} /$ diesel engine/exhaust after treatment system capable of meeting 2007 emission regulations.

The program follows a systems approach as shown in Figure 1, encompassing natural gas pre-treatment, syngas generation, liquid fuel production, product work-up/blending, and validation of the UCTF in engine tests including aftertreatment of emissions.

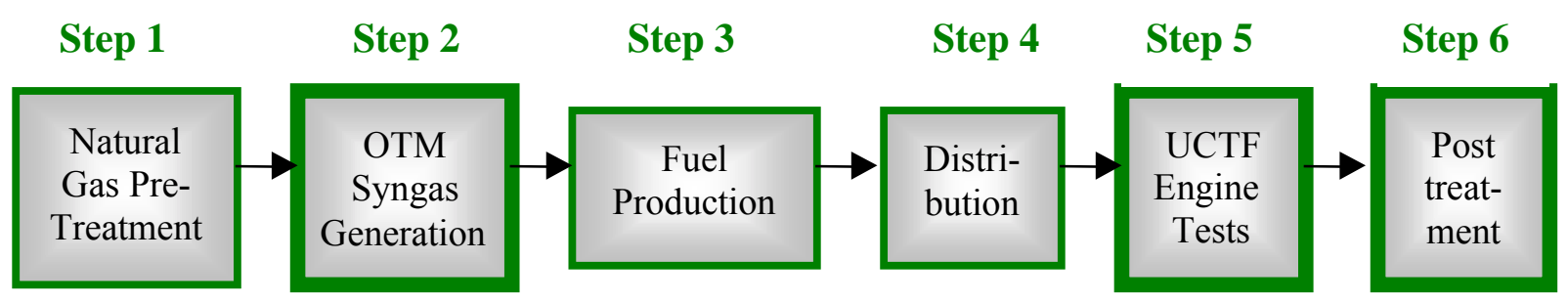

Figure 1. Systems Approach to UCTF

The 48-month project includes three parallel development or testing programs: 1) OTM syngas reactor and reactor components, OTM element fabrication and OTM syngas process development; 2) testing and co-optimization of UCTF in International Truck and Engine advanced diesel engines with exhaust post treatment; and 3) emission testing of UCTFs in a Nuvera transportation fuel cell power system. Performance objectives include:

- OTM Syngas Technology: lower capital costs, lower operating costs, lower emissions and smaller footprint compared to conventional syngas plants.

- UCTF in Advanced Diesel Engines: co-optimized system of syngas derived UCTF, diesel engine and post treatment technology targeting proposed 2007 
regulations for light and medium duty engines i.e. diesel fuel sulfur $<15 \mathrm{ppm}$; light duty engine emissions: NOx $<0.2 \mathrm{~g} / \mathrm{mi}, \mathrm{PM}<0.01 \mathrm{~g} / \mathrm{mi}$; and heavy duty engines NOx $<0.2 \mathrm{~g} / \mathrm{mi}$ and $\mathrm{PM}<0.02 \mathrm{~g} / \mathrm{bhp}$. UCTF should enable compliance with these objectives and/or lower vehicle costs.

- UCTF in a Nuvera fuel cell system: lower air emissions (on a per mile basis) based on UCTF properties such as ultra low sulfur, high aliphatic content and oxygen content.

The program has 10 major tasks, seven of which are focused on syngas technology development, one task is devoted to fuel and engine testing and optimization, one task addresses the marketing and commercialization of an UCTF system, and the final task is for program management and cost control.

The Cooperative Agreement was signed by the DOE's Contracting Officer on May 21, 2001. Budget Period 1 is January 1, 2001 through October 30, 2001. This Topical report will include results and discussions for work conducted January 1, 2001 through

September 15, 2001.

\subsection{Progress and Results by Task}

\subsection{Task 1: Materials Development}

\subsubsection{Goal - Task 1}

The Recipient shall fabricate, test and characterize OTM film and substrate materials with goal of developing a more robust and cost effective OTM element in comparison to the lead material candidate, LCM1.

\subsubsection{Milestones - Task 1}

This budget period: $1 \mathrm{Q} 01--$ Select $2^{\text {nd }}$ generation material for scale-up Status: Alternate materials have been developed with improved properties over our first generation material, LCM1. LCM1 exceeds our oxygen flux target and is suitable for continuing process and reactor development. However, a second-generation material(s) with superior mechanical properties that can withstand long-term commercial operations has not yet been selected for scale-up.

\subsubsection{Experimental - Task 1}

The search for advanced materials requires satisfying simultaneously proprietary targets in oxygen flux, creep, and thermal and compositional expansion. In addition, fracture toughness and indentation hardness are important physical characteristics, which must be optimized.

Task 1 is following an experimental plan based on proprietary knowledge of OTM materials acquired over nearly 15 years of relevant experience in the field. A number of material compositions were developed and tested during this reporting period.

\subsubsection{Oxygen Flux}


Small disk samples of the new material are fabricated for measuring oxygen flux in a permeation cell. (See Appendix pageA-1 for description and picture.) Similar cells are operational at both BP and Praxair.

\subsubsection{Creep Measurements}

A uniaxial compressive creep testing apparatus was modified at UDRI for testing ceramic pieces under a separate program with Praxair and BP. Creep measurements can be carried out at different temperatures and different loads [1]. A similar apparatus was also constructed at Praxair and is used to conduct additional tests.

\subsubsection{Dilatometry}

Dilatometry is used to measure dimension changes because of heating or changing gas composition. Thermal and chemical expansion is determined by conducting temperature and compositional scans of the subject materials in a Netzsch DIL 402E dilatometer.

\subsubsection{Fracture Toughness}

Vickers hardness was measured at loads 300, 500 and 1000g and held for 5 seconds using Model VTD11, Wolpert, Germany.

\subsubsection{Task 1 Results and Discussion}

\subsubsection{Oxygen Flux}

Oxygen flux is the most important property and first target to be reached in the development of an OTM reactor. Oxygen flux of dense discs of LCM1 and some alternative membrane candidates are given in Figure 2. It is clearly shown that the oxygen flux of LCM1 is higher than for other candidates. However according to the flux target for these discs, several of the alternative materials have sufficiently high flux to be considered as a candidate for composite membranes.

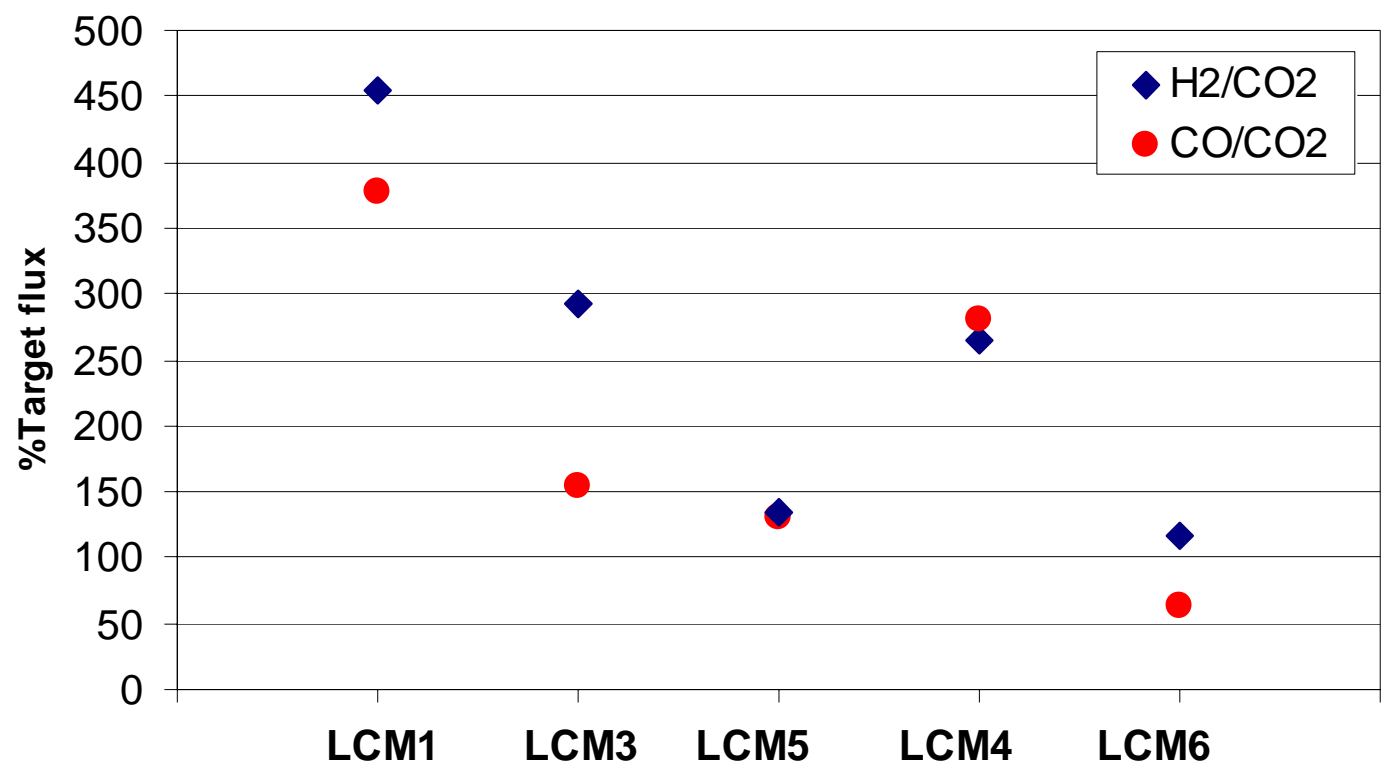

Figure 2. Flux of Lead Commercial Material Candidates 


\subsubsection{Creep Measurements}

Creep has been measured for dense LCM1, LCM2 and LCM3 at UDRI and for porous LCM1 at Praxair within this program [2]. The creep rate increases with stress (load) and temperatures as shown in Figure 3.

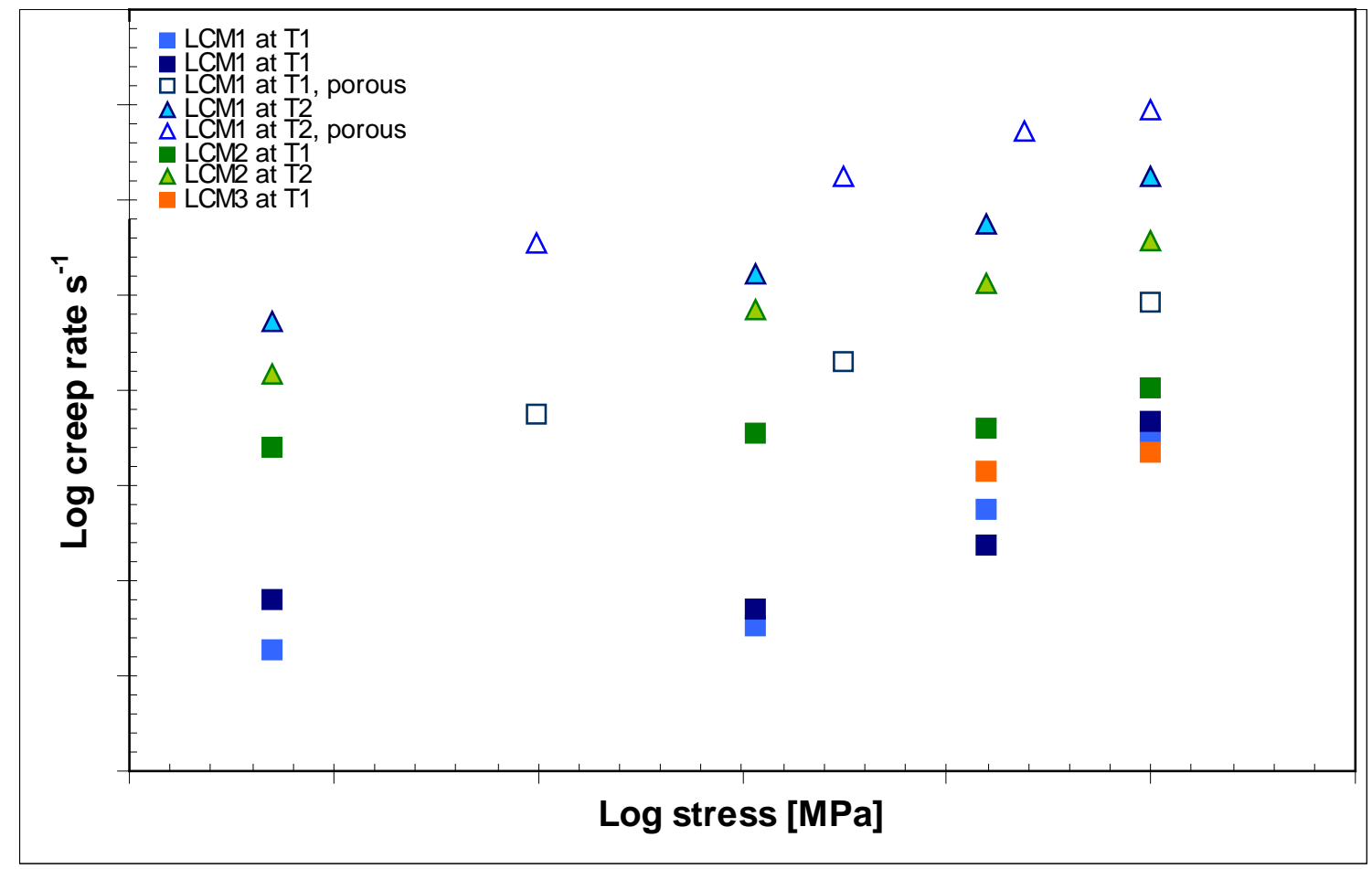

Figure 3. Creep Rate of Lead Materials as a Function of Temperature and Stress

(The target temperature is $T 1$ and $T 2>T 1$ )

At the target temperature, the lowest creep rate was measured for LCM1. A lower creep rate was expected for LCM2, however the quality of the LCM2 sample was not optimized; the creep measurement should be repeated for this sample.

The reproducibility of the creep rate was found to be good for LCM1. Porous LCM1 has about an order of magnitude higher creep rate than dense LCM1.

\subsubsection{Thermal expansion}

The expansion of a material during heating is the results of an increase in the amplitude of vibration between the atoms in the material. The thermal expansion depends on the bond strength of the material and decreases with increasing bond strength. An interesting correlation has been observed between linear thermal expansions and melting temperature of relatively close packed metal and ceramic structures. For cubic close packing, the bond strength generally increases with decreasing ionic sizes in a series of compounds with the same structure.

The thermal expansion of oxygen conducting materials includes chemical expansion from oxygen loss at higher temperatures in addition to the normal thermal expansion due to 
increased thermal vibrations. An example is given in Figure 4 for LCM3, the thermal expansion coefficient is $13 \times 10^{-6} 1 / \mathrm{K}$ below $600^{\circ} \mathrm{C}$ and increases to $19.310^{-6}$ above $800^{\circ} \mathrm{C}[3]$. The chemical expansion addition to the thermal expansion is supposed to increase with the increasing number of oxygen vacancies created during heating of the membrane material. Thus, materials with high oxygen flux will also have high thermal expansion above $600^{\circ} \mathrm{C}$, where the material starts to lose oxygen. The thermal expansion coefficients for a few membrane and substrate materials are given in Table 1 [4].

Table 1. Thermal Expansion Coefficients of Lead Material Candidates

\begin{tabular}{|l|c|c|}
\hline Material & $\begin{array}{c}\text { TEC } \\
\boldsymbol{\alpha} \mathbf{1 0}^{\mathbf{6}}\left[\mathbf{K}^{-\mathbf{1}}\right]\end{array}$ & $\begin{array}{c}\text { Temperature interval } \\
{ }^{\circ} \mathbf{C}\end{array}$ \\
\hline LCM1 & 16.9 & $25-950$ \\
\hline LCM3 & 14.4 & $25-950$ \\
\hline LCM6 & 10 & $25-1000$ \\
\hline LCM5 & 14 & $25-1000$ \\
\hline LCM7 & 12.3 & $25-1000$ \\
\hline LCM8 & 11.5 & $25-700$ \\
\hline $\mathrm{ZrO} 2$ & $\sim 10$ & Average TEC \\
\hline $\mathrm{YSZ}$ & 10.3 & $25-1100$ \\
\hline
\end{tabular}

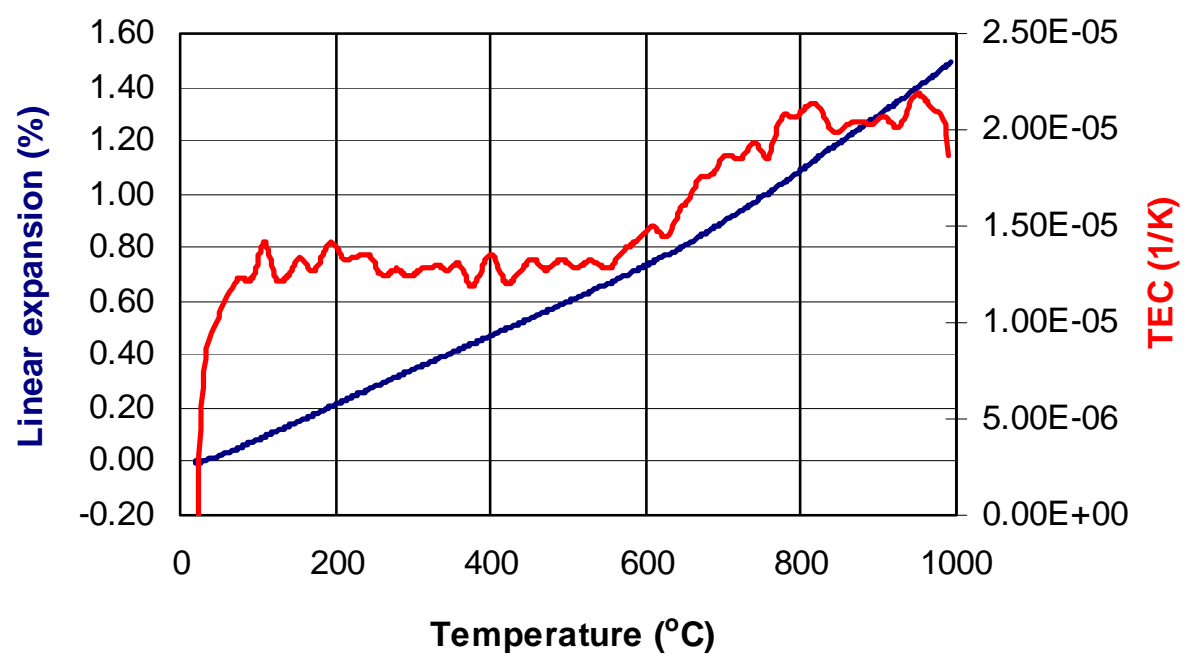

Figure 4. Thermal expansion of LCM3 as a Function of Temperature

\subsubsection{Chemical expansion}


Chemical expansion of oxygen conducting materials is caused by loss of oxygen. The oxygen content is lower at higher temperatures and at lower partial pressures of oxygen. Thus by heating the materials or lowering the $\mathrm{pO}_{2}$, the materials will expand. Chemical expansion is treated as the expansion caused by decrease in $\mathrm{pO}_{2}$. Chemical expansion of LCM1, LCM3 and LCM7 is shown in Figure 5 [5]. High chemical expansion gives rise to stresses in the membrane which is exposed to a gradient in $\mathrm{pO}_{2}$ with air on one side and fuel $\left(\mathrm{pO}_{2}=10^{-16}\right)$ on the other side. Thus it is important that the chemical

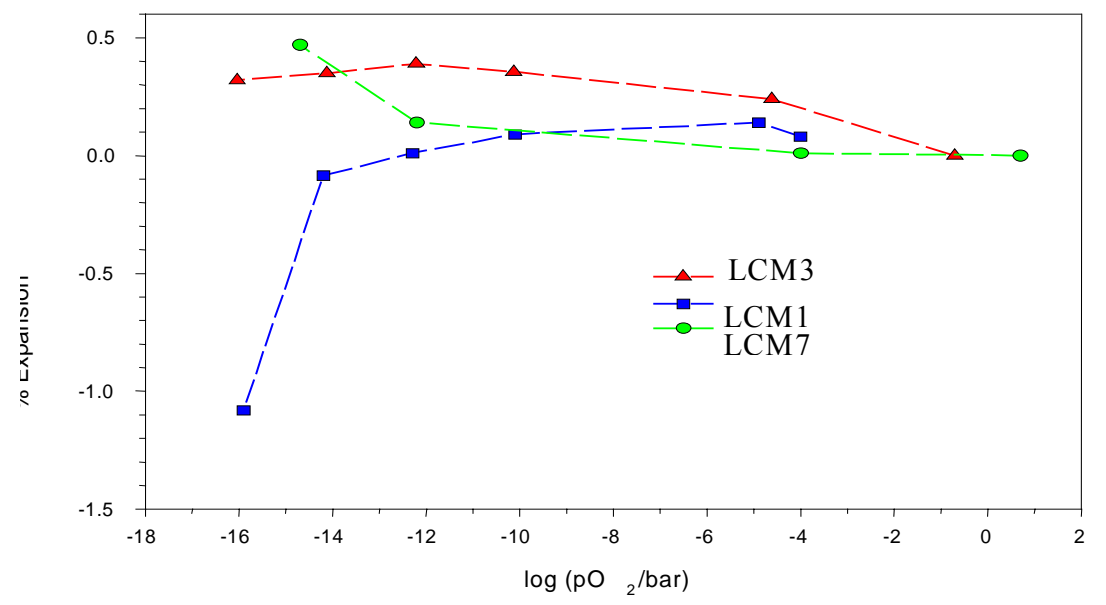

Figure 5. Chemical Expansion of LCM1, LCM3 and LCM7 vs. pO $\mathrm{O}_{2}$

expansion is as low as possible. For a dual phase or layered membrane, the match in thermal and chemical expansion is also very important. From Figure 5, one can see that there is a large mismatch in CEC of LCM1 and LCM7 at low $\mathrm{pO}_{2}$, which can be a problem with using these materials together.

Measurement of the chemical expansion of a material is time consuming; the complete chemical expansion vs. $\mathrm{pO}_{2}$ has only been measured for a few membrane materials. In the future it will be important to measure the chemical expansion coefficient of a number of candidate materials as this it is crucial to match this property for a layered and/or dual phase membrane system.

\subsubsection{Chemical stability}

The chemical stability of LCM1 and other membrane materials can be calculated from thermo dynamical data using some simple estimates for the activity of the alkaline earth metal. Methods to improve chemical stability by varying material composition are under study.

\subsubsection{Other mechanical and thermal properties}

Vickers indentation method has been used to measure hardness and fracture toughness of different membrane materials as given in Table 2 [6]. The fracture toughness is slightly higher for LCM5 and LCM3 compared to LCM1 and LCM6. Slow crack growth of ceramics is largely determined by the fracture toughness values. 
Table 2. Vickers Indentation Method Measurements (Number of indentations/cracks measured is given in brackets).

\begin{tabular}{|l|c|c|c|}
\hline $\begin{array}{c}\text { Note: All } \\
\text { results } \\
\text { normalized } \\
\text { to LCM1 }\end{array}$ & $\begin{array}{c}\text { Relative } \\
\text { Vicker's } \\
\text { Indentation } \\
\text { Hardness }\end{array}$ & $\begin{array}{c}\text { Relative Vicker's } \\
\text { Fracture } \\
\text { Toughness } \\
\begin{array}{c}\text { E = GPa1 } \\
\text { (Estimated) }\end{array}\end{array}$ & $\begin{array}{c}\text { Relative Vicker's } \\
\text { Fracture } \\
\text { Toughness } \\
\text { E=GPa } \\
\text { (Estimated) }\end{array}$ \\
\hline LCM1 & 1 & 1 & 1 \\
$(26)$ & $(11)$ & 0.78 \\
\hline LCM6 & 1.03 & 0.78 & 1.07 \\
$(12)$ & $(12)$ & 1.08 \\
\hline LCM3 & 1.17 & 1.05 & $(8)$ \\
\hline LCM5 & $(12)$ & 1.07 & $(7)$ \\
\hline
\end{tabular}

A Young's modulus of LCM1 has been measured at room temperature. Measurements at higher temperatures are in progress.

The strength of LCM1 has been measured at room temperature and measurements at higher temperatures are in progress. The mechanical properties (strength) of ceramics is known to weaken with increasing flaw size according to Griffith's equation:

$$
\sigma=A(E \gamma / c)^{1 / 2}
$$

where $\sigma$ is the fracture stress, E the elastic modulus, $\gamma$ the fracture energy, $\mathrm{c}$ the flaw size and A a constant. Generally, the flaw sizes equals the grain size of the ceramic and thus the strength decreases with increasing grain size. Thus grain size is an important parameter which must also be considered when measuring and improving strength properties.

Thermal conductivity of LCM1 has been measured at room temperature and higher temperatures. The thermal conductivity closely resembles the values of alumina.

\subsubsection{Task 1 Conclusions}

Physical characterization of three candidate materials has been completed. Nearly all new material candidates under study exceed the commercial oxygen flux target. Key mechanical properties such as creep, thermal and chemical expansion and fracture toughness can be manipulated by changing the material crystalline composition. Work will continue to optimize these properties in the search of a superior material suitable for long-term commercial operations.

\subsection{Task 2: Composite Element Development}

\subsubsection{Goal - Task 2}


Develop advanced composite OTM elements (tubes) and the techniques for fabricating these elements at the bench scale. The goal is to develop robust, low cost, high flux tubes that can survive multiple cycles in temperature and fuel composition while maintaining structural integrity at target pressure differentials.

\subsubsection{Milestones - Task 2}

This budget period: 3Q01-- Select composite structure and manufacturing technique for $2^{\text {nd }}$ generation material

Status--Several methods have been developed that are suitable for manufacturing advanced element designs. However since a $2^{\text {nd }}$ generation material or suites of materials have not yet been selected, a fabrication technique cannot yet be decided.

\subsubsection{Experimental - Task 2}

In order to develop high quality OTM tubes, characterization and testing of incoming powders (Powder Quality Control) must be conducted. The following measurement apparatus will be utilized:

- Inductively Coupled Plasma Analysis (ICP) - Stoichiometry and impurities

- X-ray Diffraction (XRD) - Phase purity

- Microtrac - Particle size distribution

- BET - Surface area

- Scanning electron microscope (SEM) - Particle morphology

- Thermo-gravimetric Analysis (TGA) - Organic content and water loss

After characterization, the powders are mixed into workable pastes and formed into disks or tubular shapes utilizing methods developed in previous Praxair programs. The OTM disks or tubes are then sintered in a controlled atmosphere at a controlled rate of heating in a high temperature muffle furnace. The sintered tubes then undergo tube characterization where a battery of tests are conducted to determine strength, diameter, straightness, flaws, phase purity and absence of leaks.

\subsubsection{Task 2 Results and Discussion}

Composite membrane structures are under study as a means to satisfy both the flux and strength requirements of a commercial ceramic OTM element. A composite structure employs a dense OTM film on a porous substrate. The porous substrate allows feed gases to permeate to the dense film where oxygen exchange and bulk diffusion through the ceramic OTM material occurs. Figure 6 is a plot of oxygen flux versus substrate thickness for two levels of dense film thickness at the commercial target temperature. For these conditions, the oxygen flux is proportional to substrate depth and insensitive to dense film thickness.

Oxygen flux through a composite membrane is a strong function of both temperature and composite membrane architecture. Figure 7 shows that the target oxygen flux can be met with a variety of composite membrane architectures and a significant range of temperatures. 


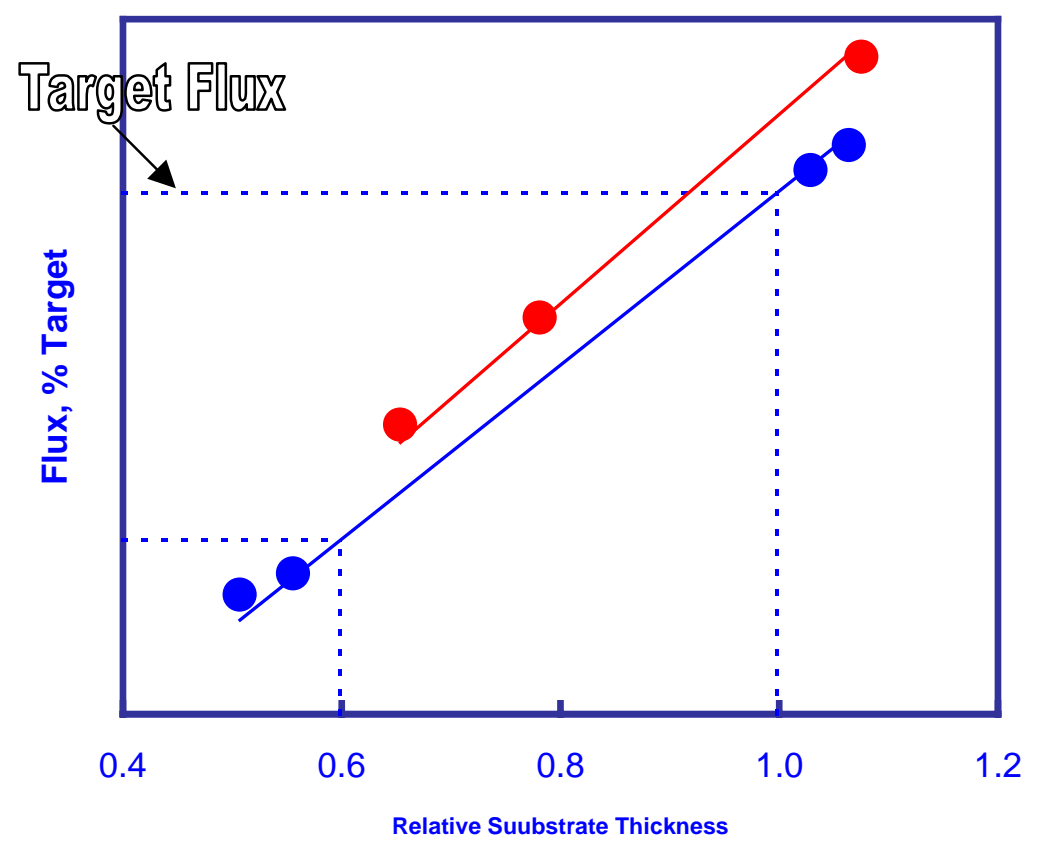

Figure 6. Flux of LCM1 and LCM2 Disks versus Substrate Thickness

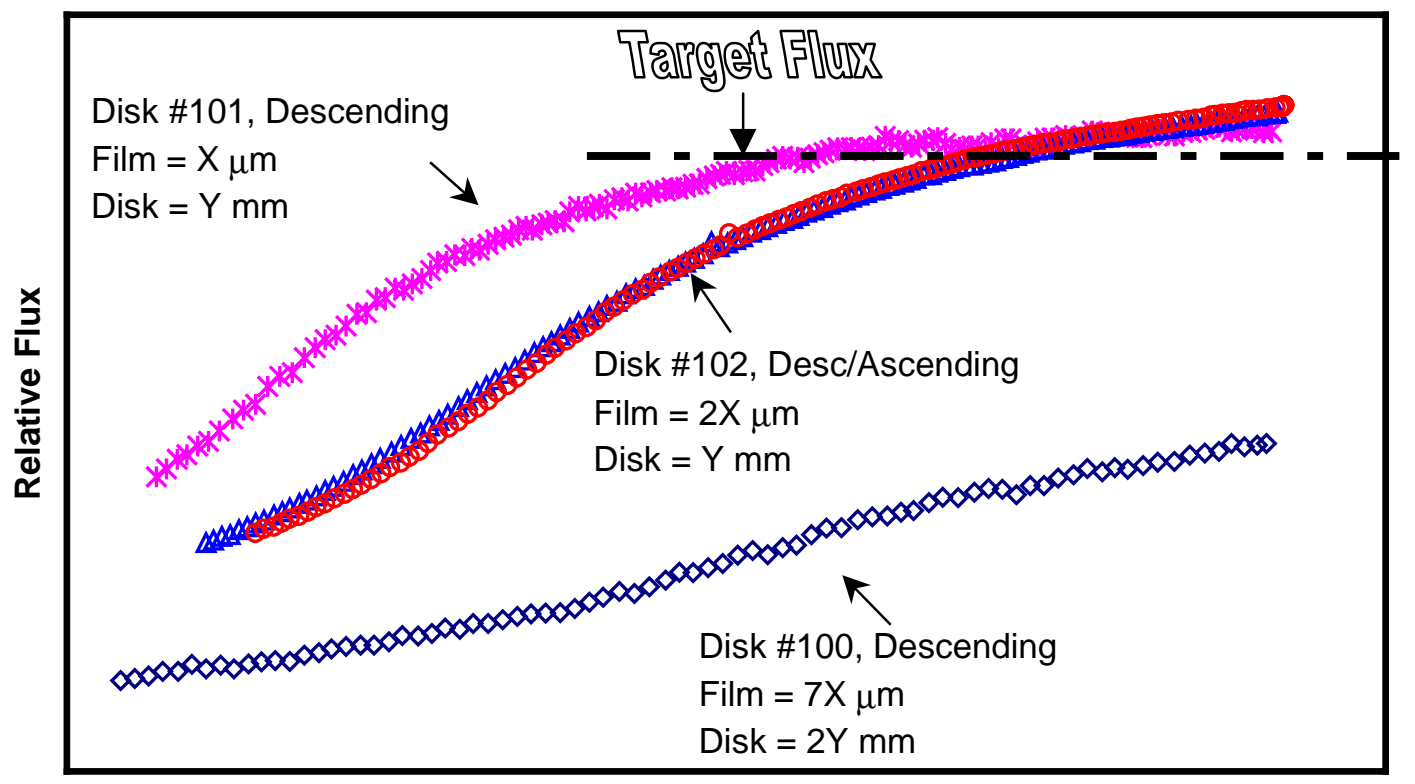

Dimensionsless T

Figure 7. Flux of LCM2 Disks versus Temperature

Three proprietary methods of fabricating composite membrane structures are currently under study. All methods have proven capable of applying leak free dense films to porous substrates. Differentiating parameters include costs, yield of leak free tubes, dimensional consistency and tube robustness, among others. So far, the method of 
fabrication has not had a large observable effect on the flux performance of the elements. A key milestone is selection of the best method for scale-up in the next budget period.

\subsubsection{Task 2 Conclusions}

Flux is influenced by both temperature and tube architecture. Target oxygen fluxes can be met with a variety of tube architectures and fabrication methods. At least three fabrication techniques are capable of making leak free composite tubes. One of these methods will be selected for scale-up to produce large elements for large scale pilot plant testing.

\subsection{Task 3: Tube Fabrication}

\subsubsection{Goal - Task 3}

The main goal is to scale-up the manufacturing process and supporting technologies for building large-scale composite tubular elements. This team will also supply elements for testing in the P-0 (6 to 8 inches), LTT, P-1 (4 to 6 feet) and P-2 reactors (6 to 10 feet).

\subsubsection{Milestones - Task 3}

This budget period: None.

Status: Prototypical membranes with dense layers ranging from $\mathrm{X}$ to $3 \mathrm{X}$ micron and porous layers ranging from $\mathrm{Y}$ to $1.67 \mathrm{Y}$ micron have been produced as tubes ranging from 20 to $140 \mathrm{~cm}$ long from LCM1 and LCM2 candidate materials.

Next Milestone: Scale-up second-generation material to make tubes adequate for P1 size reactor.

Status: Scale-up has been hampered by the delay in finalizing the chemistry of the second-generation material. However, substantial progress has been made with generic materials to enable rapid change over to the new material.

\subsubsection{Experimental - Task 3}

3.3.3.1 Green Forming: The scale-up effort centered on isostatic pressing as the green forming process to make the substrate. The dense film was then applied to the substrate using a variety of different processes. The different processes have limitations on the minimum and maximum layer thickness and hence the appropriate technique can only be finalized after the tube architecture and material are finalized.

The isostatic press is capable of making up to $3500 \mathrm{~cm}$ long tubes and is large enough to handle about 5 tubes simultaneously. The press has a maximum operating pressure of $345 \mathrm{Mpa}$. [50ksi] pressure, which is adequate for most ceramic processes.

This press is generally reserved for making longer elements. The tubes for the shorter P0 reactors are made in a smaller press which is capable of a larger range of pressures. Isostatic pressing enables the making of tubes with an open end designed to assist in sealing. 
The isostatic press and an example of a green pressed tube are shown in Appendix 5.a. page A-5.

3.3.3.2 Sintering: Sintering is performed in vertical furnaces where the tubes are hung from refractory supports. The furnaces are loaded and unloaded from the top and the atmosphere in the furnace can be controlled. Typically, the sintering process starts with slow heating in air to oxidize, evaporate and or burn the organic additives, the adsorbed water. This step has to be slow in order to ensure that the departing species do not physically damage the ceramic component, which is weakened by the removal of the binders.

After the organic constituents are removed, the furnace atmosphere can be changed to ensure that the stresses introduced by the thermal and compositional effects do not affect the ceramic. The tubes are sintered at a temperature above the target temperature, held at the temperature for 4 hours and then cooled gradually to room temperature. The temperature and the oxygen partial pressure inside the furnace are monitored continually. The sintering process results in shrinkage of about $20 \%$ in the length of the tubes. A picture of the sintering is shown in Appendix 5.b on page A-6.

\subsubsection{Task 3 Results and Discussion:}

The experimental work has been useful in defining the processing route for the Lead Candidate Material \#1 (LCM1). Several process improvements were made; new fixtures were designed and made to enable the green forming, extraction and handling of the green tubes. Two critical issues remain in this area: wall thickness uniformity and control over pore former segregation along the length of the substrate. Since the pore former has a size distribution, there is always a possibility that a larger piece will be in an area immediately behind the dense film creating a region of local weakness after sintering.

Sintering of short tubes is performed in smaller furnaces where the tubes are supported on a ceramic sagger. Thus, the side of the tube in contact with the sagger behaves differently than the rest of the tube because of friction during shrinkage and the difficulty in the removal of organic material. The weight of the tube results in some deformation during sintering. The yield of composite tubes is therefore quite low [20\%] but is adequate for small scale testing.

Longer elements are sintered in hang fire furnaces in Indianapolis. The challenge there is to support the tubes without creating high local stresses which could break the tube after the binder is removed but before the tube is sintered. The support also has to ensure that the tube shrinks uniformly and thus remains straight.

The experiments have also provided some guidance that will be useful to accelerate the scale up work on the second-generation material. This was accomplished by developing some sintering experience on generic LCM2 materials. Further development work will continue upon specification of the second-generation material. 


\subsubsection{Task 3 Conclusions}

The ability to manufacture long composite elements with an open end designed for sealing has been developed. This process has been used to make membrane elements for evaluation in the P-0, LTT and P-1 reactors. The elements have excellent straightness and roundness.

Deposition of the dense film on the inside has also been successfully demonstrated. One important finding was that when the dense layers are thin the yield after sintering is low. Future work will be directed at finding ways to improve the yield.

\subsection{Task 4: Reactor Design and Process Optimization}

\subsubsection{Goal - Task 4}

Develop the commercial OTM syngas process including reactor design and catalyst deployment, reactor components (seals, internals, isolation devices, high temperature tube sheet, etc), and ancillary processes (feed pre-treatment, pre-heat, syngas cooling). This team shall develop and employ mathematical models to simulate process conditions (reactor flow conditions, kinetics, heat and mass balances) and the mechanical, thermal and compositional stresses on the reactor components and elements. These models will enable evaluation of various conceptual designs and facilitate detailed design and evaluation of preferred options. Task 4 includes the operation of the small bench scale units, P-0, which are used to evaluate small OTM elements (6 inches long) and develop engineering data for reactor scale-up. It also includes the resources to build and operate the long tube tester.

\subsubsection{Milestones - Task 4}

This budget period: 2Q01: Start-up the Long Tube Tester (LTT)

Status--Start-up began in early $3^{\text {rd }}$ quarter. Shakedown continues, with ceramic (OTM) tube tests expected to commence before the end of September.

Next budget period: 4Q01: CFD model validated; conceptual commercial design complete.

\subsubsection{Experimental - Task 4}

3.4.3.1 P-0 Tests

The single tube tester consists of a tubular shell inside a tubular furnace that provides heat and temperature control. The shell is capable of allowing pressurized tests. The tube is sealed to fittings that separate the two sides of the membrane and prevent flow communication. Inlet gas composition, pressure, and temperature are controlled and outlet gas composition, pressure, and temperature are measured. Thermocouples are also located inside the reactor to monitor temperature. A gas chromatograph is used to measure gas compositions. See Appendix 2 page A-1 for an example of a single tube reactor.

\subsubsection{Long Tube Tests}


The Long Tube Tester (LTT) is designed to test a commercial scale ceramic oxygen transport membrane (OTM) in the production of synthesis gas using natural gas, air and steam. The LTT consists of an electrically heated reactor, a feed heater, discharge coolers and various controls, all of which are located within a ventilated enclosure. The unit will demonstrate the viability of most aspects of the OTM technology including the membranes, catalysts, seals and process parameters. For a view of the LTT see Appendix 3 page A-3.

\subsubsection{Seal Tests}

The unique material properties of the OTM elements make sealing a particularly challenging task, especially in the application of bonded seal technology such as diffusion joints, brazes, or glass sealants. For this reason, the OTM alliance has focused primarily on non-bonded compression joints. Although the compression joints generally are not as leak-tight as bonded seals, they are more versatile and can better accommodate the current OTM elements. At this time, versatility in the seal technology is particularly important since the OTM elements are themselves still under development.

OTM alliance compression seal performance is tested in single element P-0 reactors (described above), the multi-element $\mathrm{P}-1$ reactor, and designated seal test reactors. The latter are used to evaluate new concepts and address important issues related to longevity and thermal cyclability of the seals.

As in P-0 reactor tests, small OTM elements (6-8 inches long) are used in seal test reactors, which include replicas of the seal fixtures used in the multi-element P-1 reactor. Seal tests are performed at up to target temperature and a pressure differential up to slightly greater than target pressure in either air or nitrogen. Mass flow measurements are used to determine leak rates. In addition, coupon tests under compression are performed to study interaction between sealant and OTM materials.

\subsubsection{Modelling Studies}

A computational fluid dynamics (CFD) model has been developed for the P-0 reactor. This is a traditional laboratory scale reactor with axial flow in a cylindrical pipe heated by a radiation furnace. Inside the reactor shell, on the axis of symmetry, is a closed end oxygen transport membrane (OTM) tube. To enable axial circulation of air inside the OTM tube, an opened end lance tube is inserted as depicted in Figure 8. Typically, air at low pressure flows up through the annulus formed by the lance and OTM and down through the lance. Fuel at high pressure flows down through the annulus formed by the OTM and the reactor shell. As a result of the difference in chemical potential across the membrane, oxygen permeates through the wall and reacts with the fuel on the surface of the OTM tube. 


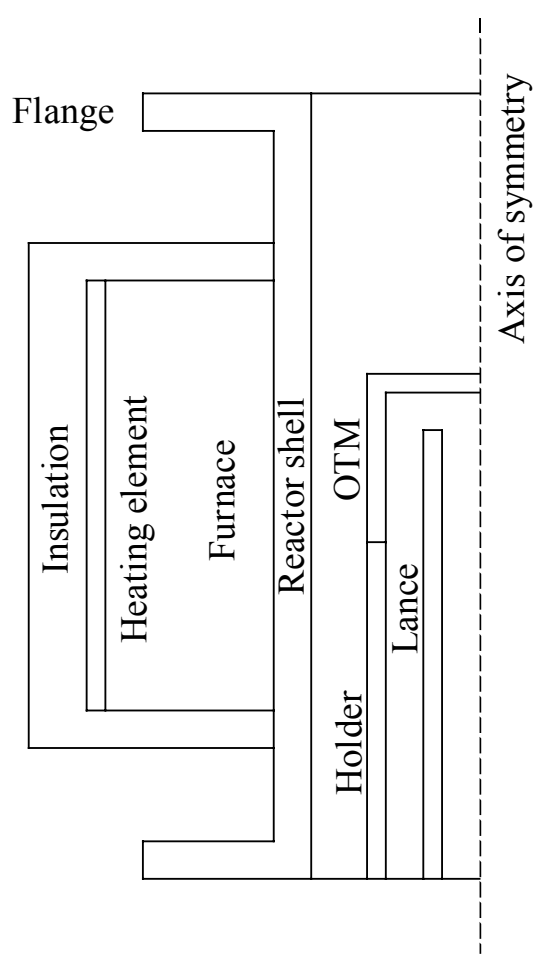

Figure 8. Schematic Diagram of P-O Reactor

The flow fields inside the reactor are axisymmetric, but not one dimensional, because the air stream changes from upflow to downflow at the top of the lance and the fuel stream has a radial velocity component at the top of the OTM tube. Both streams must be treated as multi-component because the oxygen concentration in the air stream is changing due to permeation and the fuel stream composition is changing due to combustion and reforming reactions. The computational model is complex because the physical and chemical processes in the two streams are coupled due to oxygen permeation and heat transfer through the OTM wall.

When oxygen permeates through the membrane, combustion reactions occur on the outside surface of the OTM, and the heat of reaction must be dissipated by conduction in the OTM, convection to the fluid streams and radiation to both the lance and the reactor shell. In this event, the radiation flux from the OTM to the reactor shell is significantly greater than the radiation flux from furnace to the reactor shell. Since the shell temperature is determined by the net radiation flux, it is necessary to include the radiation furnace in the reactor model. In addition, end losses of thermal radiation in the fuel stream cannot be ignored because the OTM tubes are relatively short compared to the reactor diameter. As a result of these two features, a very sophisticated radiation code is required to handle the radiation exchange between surfaces.

The P-0 reactor model is implemented in a commercial CFD code called CFX-4. The radiation problem is handled in a separate code called CFX Radiation which interfaces with CFX-4. Both codes were developed and are sold by AEA Technology. 
The equations in CFX-4 are derived from the basic conservation laws for momentum, energy, total mass balance and species mass balance. These equations are supplemented by empirically based chemical kinetics equations for the combustion and fuel reforming reactions. Another key component is the oxygen transport model which calculates the oxygen flux through the membrane as function of the difference in chemical potential across the membrane. Fluid properties are treated as functions of temperature and composition.

\subsubsection{Task 4 Results and Discussion}

\subsubsection{P-0 Tests}

$\mathrm{P}-0$ tests in 2001 have concentrated on meeting the life (1000 hour continuous operation at pressure) and cycling (10 complete thermal and compositional cycles) goals of Phase 2. Neither of these goals has been accomplished yet, but there has been substantial progress made in both areas.

A tube has been running for over 750 hours with a flux close to $70 \%$ of the Phase 2 target flux using the standard fuel mixture at $100 \mathrm{psi}$. The tube surface temperature is higher than the furnace temperature, indicating that the exothermic oxidation reaction is providing heat to the membrane. The test also included one complete compositional cycle. Another tube survived 310 hours at medium pressure. The initial flux met the Phase 2 target flux, but declined to about $70 \%$ of the target flux where it stabilized. Another tube survived for about 150 hours at medium pressure with no fuel, an additional 175 hours at low pressure with no fuel, and then 125 hours under the standard fuel mixture at a slightly lower pressure before it failed. The initial oxygen flux with the standard fuel mixture was about $80 \%$ of the Phase 2 target flux.

A thermal cycling test completed seventeen thermal cycles between room temperature and $70-100 \%$ of target temperature without leakage, but during the 18th cycle, a system failure unrelated to the membrane or seal caused the seal to fail. The total test time was almost 1000 hours. High differential pressure was maintained throughout the test. There was no leakage using the new seal design. The flux was almost half of the Phase 2 target flux and did not change significantly with pressure. The tube was removed intact upon shutdown. Another test completed 5 thermal cycles and one process gas cycle before failure after about 150 hours. Other tests have completed two or three compositional and thermal cycles. Cycling tests continue.

The single tube reactors have also accomplished other important program goals in 2001 .

At the beginning of the year, corrosion was considered an important issue. No corrosion or other new phases were found on a tube after 430 hours on stream under dynamic conditions at $90 \%$ of target temperature. The color of the tube changed slightly, probably because of some surface roughening as seen in SEM. The results from the static corrosion test in the P-0 reactor are in good agreement with earlier tests under similar conditions (same T, P, and composition) in the SCTU reactors. 
Sealing the membrane was also an important issue. A P-0 reactor was modified to operate at high pressure. The tube held high pressure at $96 \%$ target temperature for 24 hours after which the pressure was reduced to medium-high pressure and reactor temperature increased to the target temperature for 72 hours. A very small helium leak was observed.

The single tube reactors are also required to assist in the design and operation of the multi-tube reactors. A startup/shutdown protocol was specified for P-1. A much more aggressive startup procedure has been demonstrated in P-0. The oxygen flux vs. utilization was measured. The flux decreased significantly as the $\mathrm{O}_{2}$ in the inlet dropped below a threshold inlet concentration. Lower inlet oxygen concentrations led to very low oxygen concentrations at the outlet. This provided important information to the reactor design for large-scale reactors. The catalyst for the pilot reactor was specified and will be deployed on the process gas side of the membrane. The catalyst was tested with an alumina tube and gave a high, stable methane conversion at $93 \%$ of target temperature with a total fuel flow of $1.8 \mathrm{lpm}$ at atmospheric pressure. The catalyst deactivated slowly during the first 200 hours on stream, both in fuel and inert, but stabilized after 200 hours. The total length of the run was 360 hours.

\subsubsection{Long Tube Tests}

October has been reserved for testing the background activity of the cross flow reactor. In addition a 250 hour life test will be pursued at target pressure using the 'standard gas mixture'. The test will be performed at low oxygen utilization and methane conversion in order to take advantage of a higher heat removal rate under those operating conditions. The furnace temperature will be controlled to such a value that the membrane wall temperature will be below target temperature. All OTM tubes selected will be helium leak tested in order to enhance our chances for a successful test.

\subsubsection{Seal Tests}

Efforts in 2001 have been focused on deploying compression seals in the P-1 reactor and improving the ability of these seals to undergo thermal cycling. The OTM compression seal has been used successfully in a number of $\mathrm{P}-1$ reactor tests with full size OTM elements. Thermal cycling has also been demonstrated in P-0 and seal reactors; however, a number of issues have hindered consistency in cycling, especially in the P-1 reactor.

One obstacle to thermal cycling has been adverse chemical interaction between the seal materials and OTM elements. Such interactions can lead to undesirable chemical bonding, stress accumulation during cycling, and failure in the OTM elements. As expected, this becomes more problematic as the operation temperature is increased.

Several promising techniques that reduce or eliminate adverse interactions between the sealant materials and OTM elements have been investigated. The ability to make OTM compression seals that can survive thermal cycling and maintain leak rates well below the target is shown in Figure 9. Figure 10 includes data from several different seal tests that were cycled between ambient and several temperatures including the target temperature. 
The seal cycled to the target temperature included one of the techniques to prevent chemical interaction.

In addition to reducing chemical interaction between the seal materials and OTM elements, design modifications to key seal components have also improved consistency. These modifications have especially been beneficial in the ability to form seals for OTM element life-tests in the P-0 reactor. Leak rates as a function of time for seals from P-0 and seal reactor tests are shown in Figure 10. In each test, the temperature of the seal was maintained between approximately $87-100 \%$ of target temperature.

A number of other seal options are being investigated by the OTM alliance. Along with alternative compression seal designs, bonded seal technologies are also being evaluated. Bonded seals are expected to become more feasible with advances in the OTM element technology and ultimately provide the best commercial sealing option.

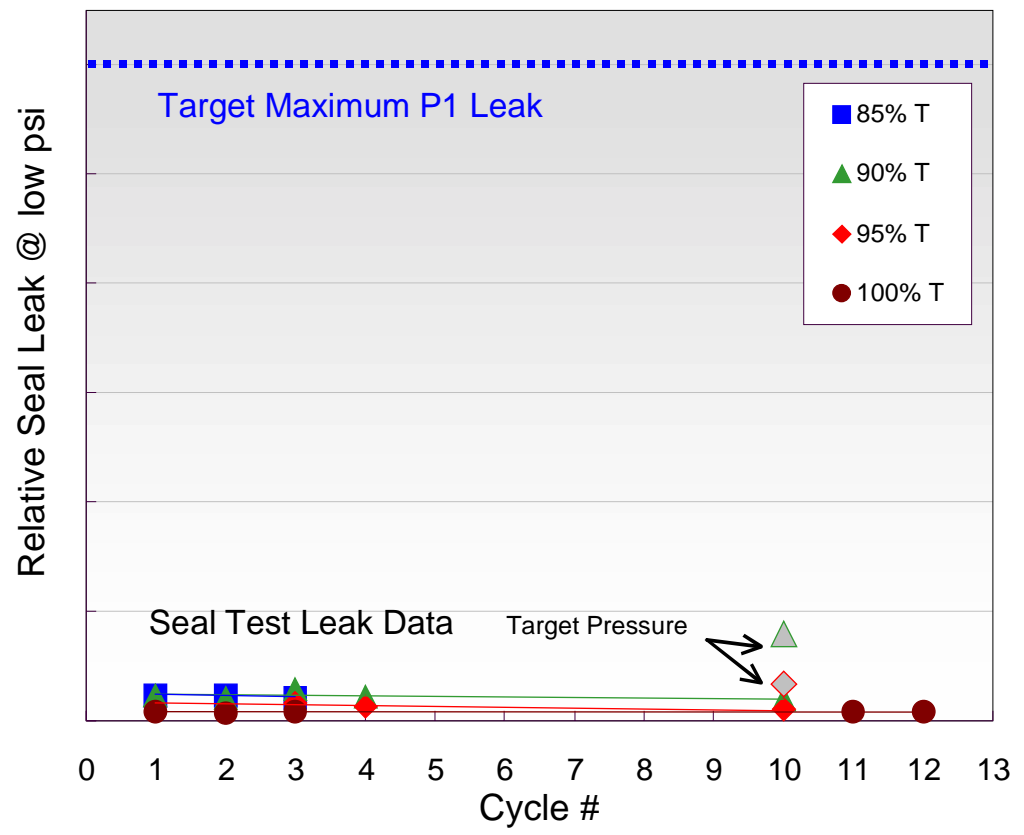

Figure 9. Relative Leak Rates of OTM Seals after Thermal Cycling

The blue dashed line indicates the target maximum leak rate for the P1 reactor. 


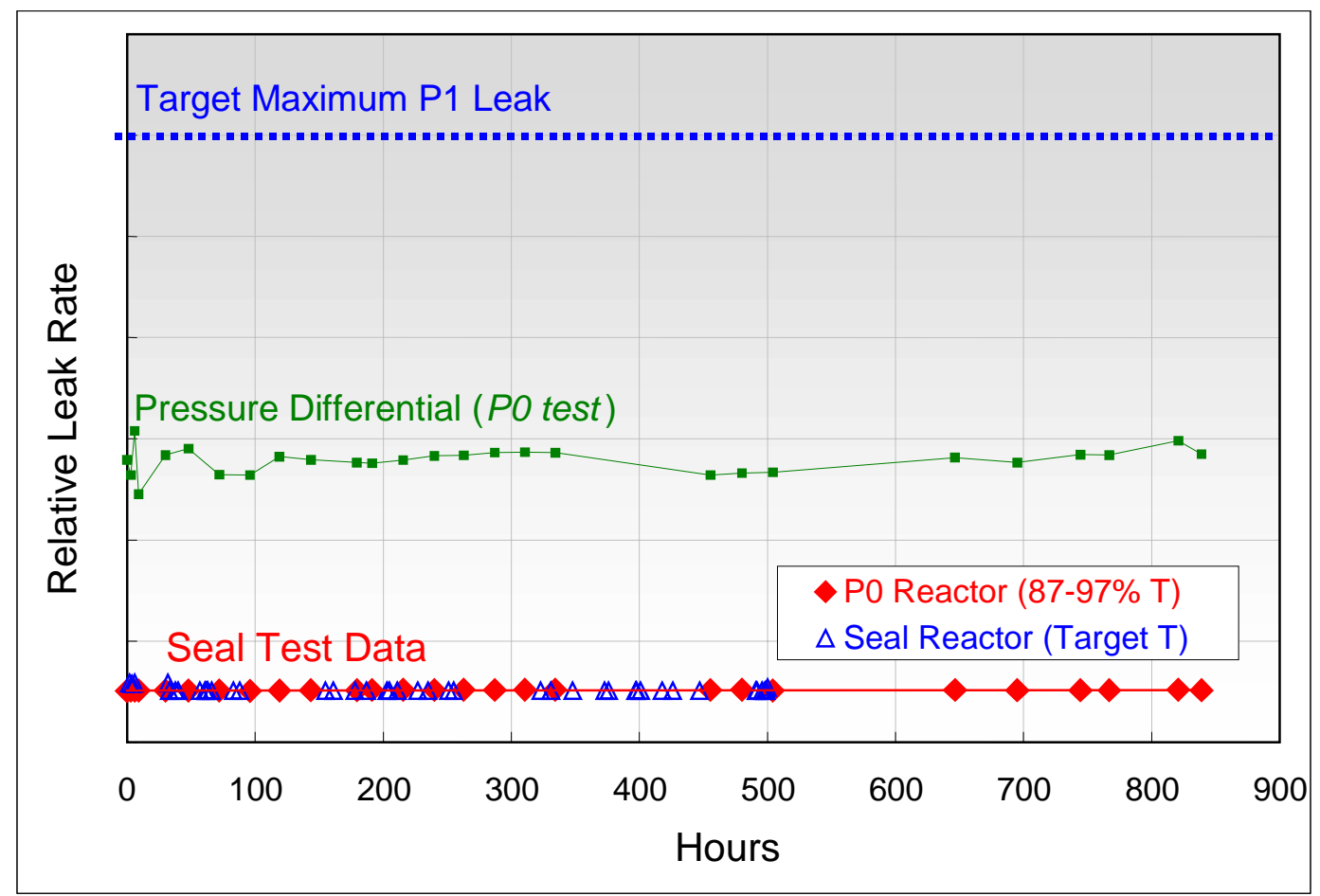

Figure 10. Relative Leak Rate as a Function of Time for OTM Seals used in the $P O$ (red) and seal test (blue) reactors.

The blue dashed line indicates the target maximum leak rate for the P1 reactor.

\subsubsection{Modelling Studies}

The P-0 model predicts the flow fields inside the reactor for both the air and fuel streams. As an example, Figure 11 shows a view of the weak counter flow vortex produced by the turning air stream at the top of the lance tube. This phenomenon produces very low velocities and oxygen concentrations above the lance. The momentum equations also give the pressure loss in each of the fluid streams. 


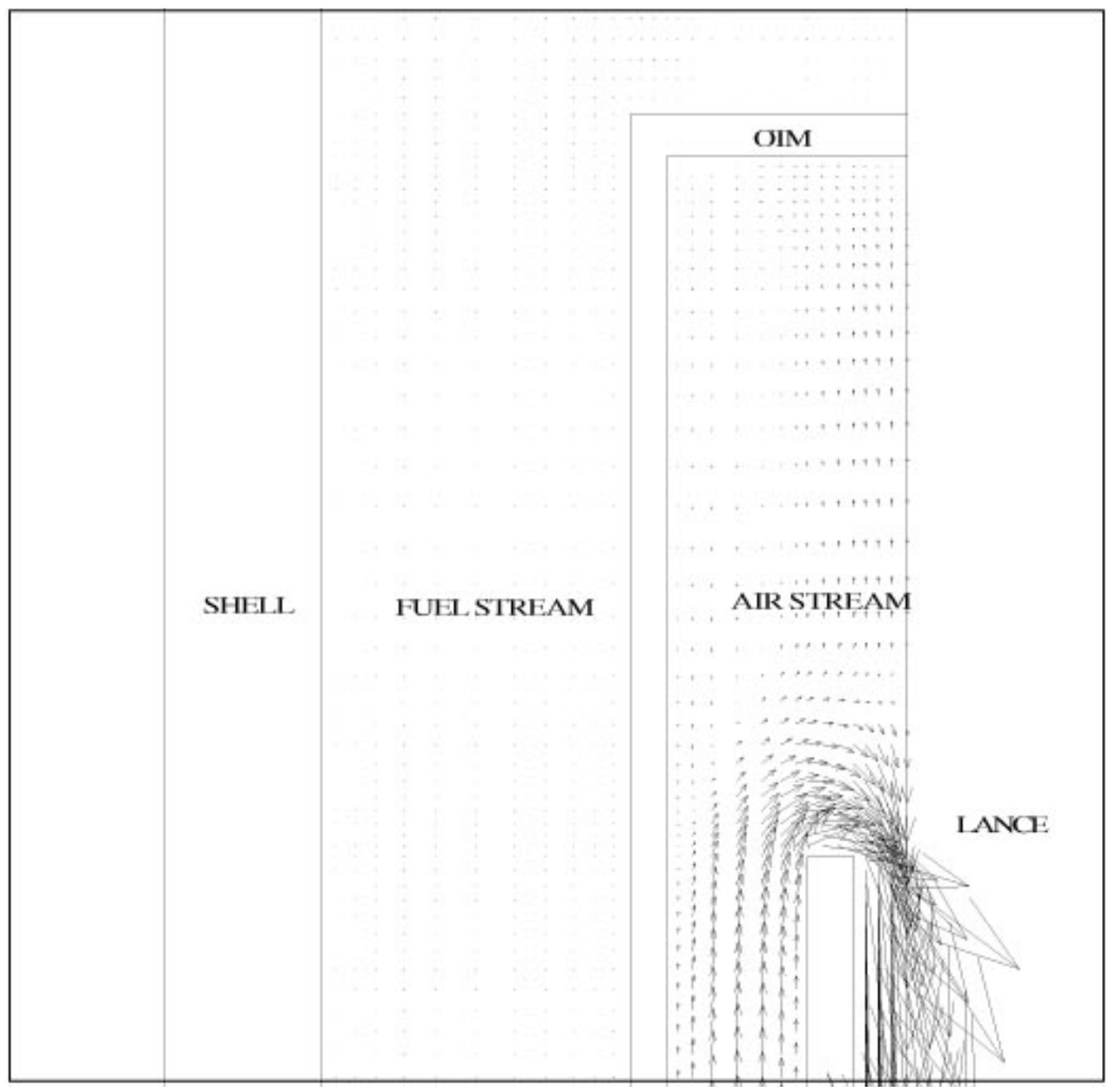

Figure 11. Velocity Vectors Showing the Recirculation Zone above the Lance Entrance

Another important parameter is the temperature distribution in the OTM wall. This is a two-dimensional field varying in both the radial and axial direction. It is computed by the CFD code from an energy balance which accounts for the heat of reaction, conduction, convection and radiation exchange with the surroundings. Figure 12 shows the temperature contours near the top of the OTM tube. In this case the temperatures range from a low of about $86 \%$ of target temperature in the fuel stream to a high of about $116 \%$ of target temperature in the OTM tube. The contour lines are separated by $20^{\circ} \mathrm{C}$ intervals. The wall temperature is important because it affects the rate of oxygen permeation, and more importantly, it affects the structural stability of the OTM tube. 


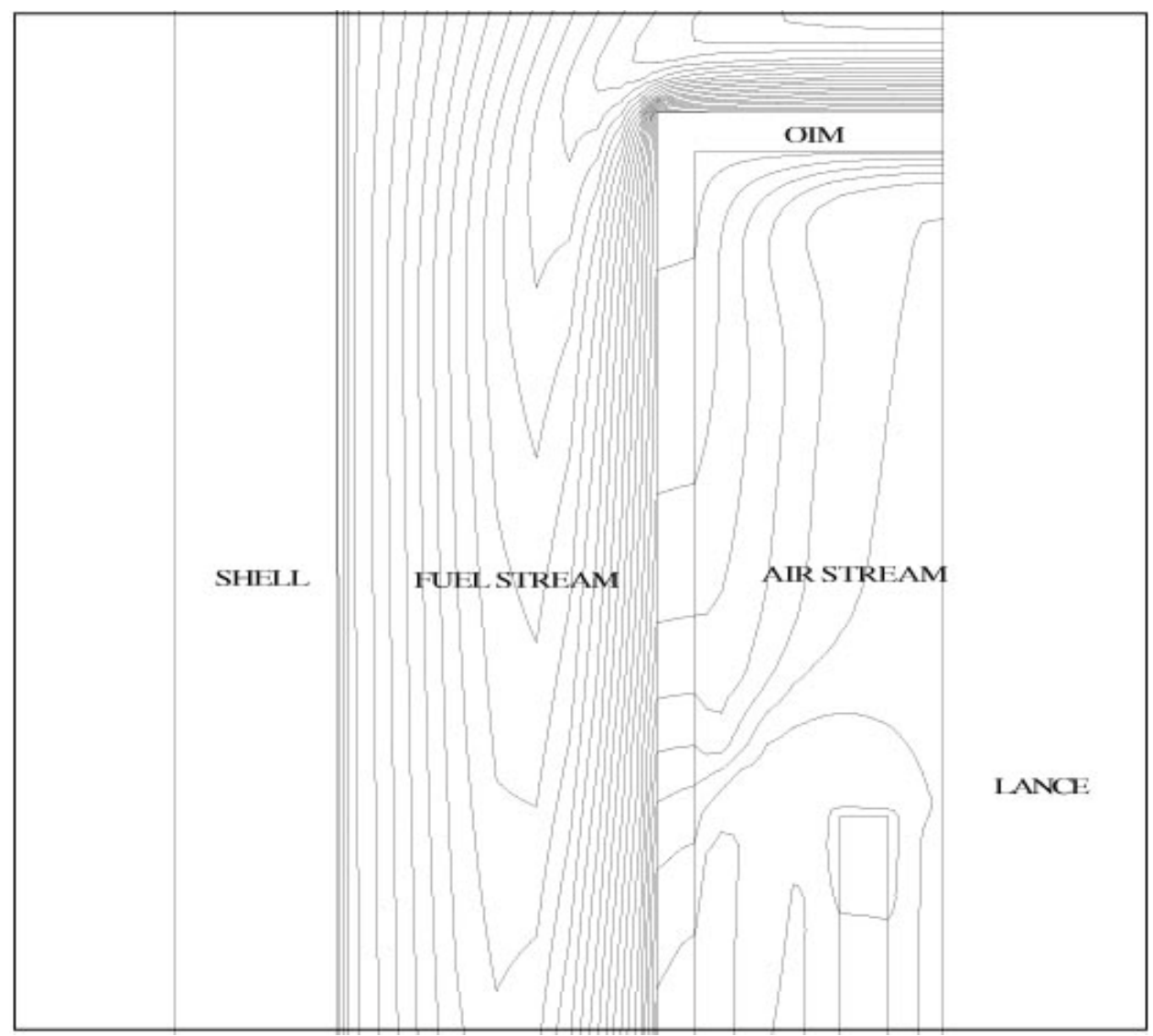

Figure 12. Temperature Contours at the Top of the OTM Tube

The model is also capable of predicting the oxygen concentration in the air stream and the species concentrations in the fuel stream. These concentrations change as a function of axial and radial position as a result of oxygen permeation and chemical reactions. The reaction rates are determined in separate laboratory experiments, and then are inserted into the CFD code as empirical correlations. This capability enables one to examine the effect of operating conditions and design parameters on the performance of the reactor.

As discussed in the above paragraphs, the purpose of the computational model is to provide insight into the complex physical and chemical processes occurring in the P-0 reactor. Often the parameters affecting the performance of the reactor are not easily measured in the laboratory or are very expensive to measure. In this case the computational model provides a cost effective alternative tool. It is also useful in optimizing the performance of the reactor under changing operating conditions and design features. Finally, it provides a diagnostic tool for investigating operational problems in experimental work. Simulation runs using the model are often the only means for understanding the source of a test failure.

\subsubsection{Task 4 Conclusions}

Significant progress was made in modelling of the OTM performance in the reactor. The tube wall temperature was shown to be a critical variable impacting tube life. The tube 
wall temperature was shown to be primarily controlled by the oxygen flux and the heat transfer mechanisms from the surface. The importance of radiation and convection was delineated and preferred means to control wall temperature were identified. A novel strategy for preheating the feed gas was identified. The conceptual design of commercial reactor has been postponed

Seal and TID developments are on track. Leak rates below target and ability to cycle multiple times without seal degradation was demonstrated. A proof of concept TID was fabricated and performed well in room temperature lab tests.

While P-0 tests are behind schedule, there was significant progress in running high pressure tests with gas mixtures simulating reactor operation. The P-0 reactors have been heavily instrumented to permit detailed mapping of the thermal fields inside and outside the tube. This has permitted close control of the tube wall temperature greatly enhancing the success rate in the tests. A life test at medium pressure and target temperature is in progress and has exceeded 500 hours.

\subsection{Task 5: Catalyst Development}

\subsubsection{Goal - Task 5}

Develop the steam reforming catalyst system (and other catalysts, if so needed) employed in the OTM reactor. At least three methods of catalyst deployment will be evaluated.

\subsubsection{Milestones - Task 5}

This budget period: $2 \mathrm{Q} 01-2^{\text {nd }}$ generation catalyst system chosen for testing Status--Completed--Chose Cat A for testing

Next budget period: 4Q01-- ${ }^{\text {nd }}$ generation catalyst system installed in P-1

\subsubsection{Experimental - Task 5}

Kinetics experiments were performed in an Incoloy- $800 \mathrm{HT}$ tubular reactor (ID $=12 \mathrm{~mm}$, length $=20 \mathrm{in})$ heated by a three-zone Thermcraft furnace. Gases $\left(\mathrm{CH}_{4}, \mathrm{H}_{2}, \mathrm{CO}, \mathrm{CO}_{2}\right.$, $\mathrm{He}$ ) were fed to the reactor using Brooks mass flow controllers. Steam was supplied to the reactor using an ISCO pump and heat-traced sample lines. The water vaporization section of the reactor was maintained at $175^{\circ} \mathrm{C}$ with heating tape. $1 / 16^{\prime}$ stainless steel tubing was used to connect the ISCO pump outlet to the water vaporization inlet in order to assure a steady flow of liquid water into the reactor system. The inlet gases were mixed with the steam in the water vaporization section. Steady flow of water into the system is essential for stable operation. The high surface tension of water results in a tendency to form large drops of liquid. This can result in intermittent bursts of steam into the reactor system. Steady state gas flow out of the reactor provides a good indication that the bursting effect is minimized.

The tubular reactor was lined with an alumina sleeve (11 $\mathrm{mm}$ OD, $8 \mathrm{~mm}$ ID) in order to minimize gas contact with the active metal surface. Background runs with no catalyst in the system consistently showed low activity for methane conversion $(<5 \%)$. Zirconia wool was used to plug the alumina tube near the reactor outlet and alumina powder 
(50/60 mesh) was layered on top of the zirconia wool up to the axial location desired for the catalyst bed (close to the center of the furnace). A thermocouple was fed through the top of the reactor and adjusted to rest in the center of the catalyst volume.

Steam was condensed out of the effluent in a stainless steel vessel immersed in an ice bath. Condensation occurred before a backpressure regulator valve released the gases to atmospheric conditions. The gases were analyzed using an MTI gas chromatograph equipped with a TCD detector. Water flow was calibrated gravimetrically. Gas flows were measured under ambient conditions using a digital bubble-meter and corrected to STP conditions. Carbon balances were generally $95 \%$ or greater.

Catalyst samples were cut and in some cases crushed to fit in the reactor. The samples were arranged in the reactor to minimize reactant gas bypass and allow for flow-through conditions. The mass of catalyst tested was usually in the range of 0.1-0.5 g. Flow rates were scaled from the values expected for commercial reactor designs.

\subsubsection{Task 5 Results and Discussion}

The purpose of a catalyst in this reactor system is to promote both steam methane reforming and the water-gas shift reactions:

$$
\begin{array}{r}
\mathrm{CH}_{4}+\mathrm{H}_{2} \mathrm{O} \leftrightarrow \mathrm{CO}+3 \mathrm{H}_{2} \\
\mathrm{CH}_{4}+2 \mathrm{H}_{2} \mathrm{O} \leftrightarrow \mathrm{CO}_{2}+4 \mathrm{H}_{2}
\end{array}
$$

Note that Equation (3) is simply Equation (2) plus the water gas shift reaction. The empirical rate equations are of the following form:

$$
\begin{aligned}
& \text { CO Reaction Rate }=\mathrm{k}_{\mathrm{o} 1} \exp \left(\frac{-\mathrm{Ea}_{1}}{\mathrm{RT}}\right) \mathrm{P}_{\mathrm{CH} 4}^{\mathrm{a} 1} \mathrm{P}_{\mathrm{H} 2 \mathrm{O}}^{\mathrm{b} 1} \mathrm{P}_{\mathrm{H} 2}^{\mathrm{c} 1} \mathrm{P}_{\mathrm{CO}}^{\mathrm{d} 1}\left[1-\frac{\mathrm{P}_{\mathrm{H} 2}^{3} \mathrm{P}_{\mathrm{CO}}}{\mathrm{K}_{\mathrm{smr} 1} \mathrm{P}_{\mathrm{CH} 4} \mathrm{P}_{\mathrm{H} 2 \mathrm{O}}}\right] \\
& \mathbf{C O}_{2} \text { Reaction Rate }=\mathrm{k}_{\mathrm{o} 2} \exp \left(\frac{-\mathrm{Ea}_{2}}{\mathrm{RT}}\right) \mathrm{P}_{\mathrm{CH} 4}^{\mathrm{a} 2} \mathrm{P}_{\mathrm{H} 2 \mathrm{O}}^{\mathrm{b} 2} \mathrm{P}_{\mathrm{H} 2}^{\mathrm{c} 2} \mathrm{P}_{\mathrm{CO}}^{\mathrm{d} 2}\left[1-\frac{\mathrm{P}_{\mathrm{H} 2}^{4} \mathrm{P}_{\mathrm{CO} 2}}{\mathrm{~K}_{\mathrm{smr} 2} \mathrm{P}_{\mathrm{CH} 4} \mathrm{P}_{\mathrm{H} 2 \mathrm{O}}^{2}}\right]
\end{aligned}
$$

where $\mathrm{P}_{\mathrm{CH} 4}, \mathrm{P}_{\mathrm{H} 2 \mathrm{O}}, \mathrm{P}_{\mathrm{H} 2}, \mathrm{P}_{\mathrm{CO}}, \mathrm{P}_{\mathrm{CO} 2}$ are partial pressures in atmospheres, $\mathrm{T}$ is temperature in Kelvin, $\mathrm{K}_{\mathrm{smr} 1}$ and $\mathrm{K}_{\mathrm{smr} 2}$ are the equilibrium constants for Reactions (2) and (3) in atmospheres $^{2}$, $\mathrm{R}$ is the gas constant, and $\mathrm{k}_{\mathrm{o} 1}, \mathrm{k}_{\mathrm{o} 2}, \mathrm{Ea}_{1}, \mathrm{Ea}_{2}, \mathrm{a} 1, \mathrm{a} 2, \mathrm{~b} 1, \mathrm{~b} 2, \mathrm{c} 1, \mathrm{c} 2$, d1, and $\mathrm{d} 2$ are empirical constants whose values are determined by standard regression techniques. Reaction rates calculated from Equations (4) and (5) are in units of moles $/ \mathrm{m}^{3}$ reactor/s. Rates for the other gas components can be determined from the $\mathrm{CO}$ and $\mathrm{CO}_{2}$ rates using the reaction stoichiometry. By taking the logarithm of both sides of Equation (4) and (5), the reaction rates predicted by the catalyst model can be correlated to the various pre-exponential factors, activation energies, and pressure exponent terms using multiple linear regression. This yields a simpler model, which is more readily deployed 
in our advanced CFD reactor models. A comparison of the rigorous model and the regressed model is shown below in Figure 13.

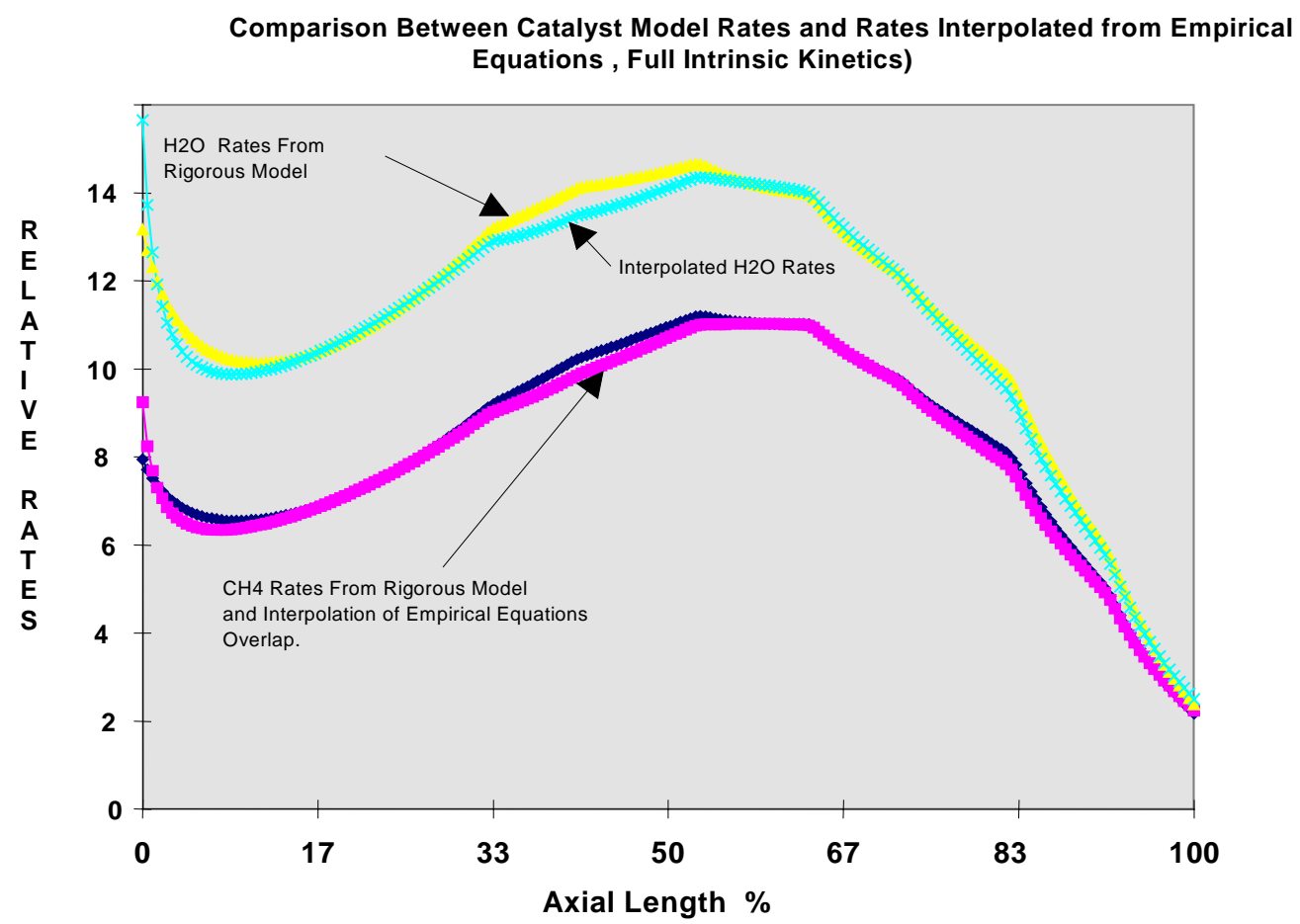

Figure 13. Comparison of Rigorous and Empirical Kinetic Model

Four types of catalyst systems are under study for this program, CatA, CatB, Cat C and Cat D. Reaction rates are measured and fitted to equations 3 and 4 for each these catalyst systems utilizing the apparatus and methods described above. The kinetic rates are then incorporated into various reactor models to determine the effectiveness of that catalyst under a variety of expected process and flow conditons. So far, Cat A and Cat B have been studied extensively. Each catalyst exhibits activity levels above that needed for operation of P-1, as shown below in Figure 14 for CatA over a wide range of feed methane concentrations and temperatures. (Each curve represents a different $\mathrm{T}$ and/or pressure) CatB exhibited a similarly robust activity profile. 


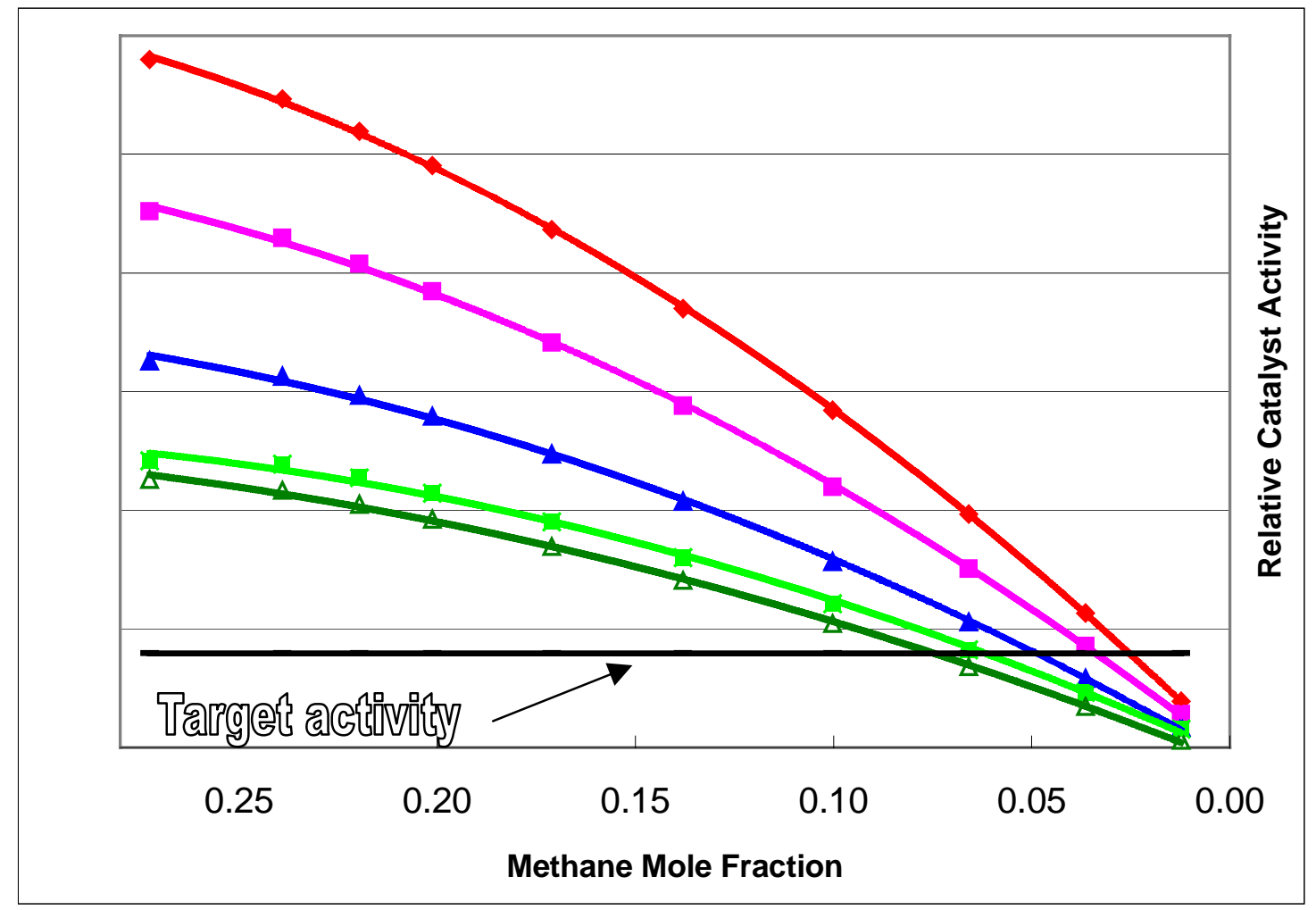

Figure 14. CatA Relative Activity versus Target Activity over a Range of Temperature

In addition, cycling and aging studies are underway to determine catalyst life and stability during both steady state and transient conditons. Although these studies are still underway, both catalyst systems (CatA and CatB) are performing well. Each catalyst appears to have sufficient activity, life and stability for P-1 operations. CatA has been chosen for near term test work in the LTT and P-1 based on it's availability, cost, activity, ease of use and compatibility with OTM elements and reactor components

Work will continue to assess life and stability of CatA and CatB. Similar evaluations of CatC and CatD will be undertaken in Budget Period 2. Final selection of a catalyst system for a commercial process will be based on a number of factors, including cost, ease of deployment, regeneration or replacement, life, stability, activity, susceptibility to and compatibility with reactor components and OTM elements.

\subsubsection{Task 5 Conclusions}

The catalyst development program has yielded a number of exciting options for satisfying the catalytic needs of proposed OTM reactor designs with unique deployment requirements. Two catalyst systems, CatA and CatB, exhibit adequate activity, life and stability for use in P-1 pilot plant operations.

\subsection{Task 6: P-1 Operation}

\subsubsection{Goal - Task 6}


Run the newly constructed P-1 to demonstrate the technical feasibility of the OTM syngas technology under steady state and transient conditions. P-1 will be commissioned, shaken down, and operated with several tubes in BP1. The unit will be revamped end of year and outfitted with a full complement of tubes. (The composition, design and fabrication technique of these tubes will have been validated in the LTT).

\subsubsection{Milestones- Task 6}

This budget period: 3Q01--P-1 achieve steady state with low tube count of $1^{\text {st }}$ generation materials, elements, and catalyst.

Status--Partially Complete--Steady state was achieved with two first generation tubes and an inert catalyst material. The unit achieved steady state operation for over 100 hours, but about $100^{\circ} \mathrm{C}$ below target temperatures. The unit was successfully cycled without a tube failure.

Next budget period: 4Q01--Design modifications for revamp of P-1 completed.

\subsubsection{Experimental - Task 6}

See Appendix 4 page A-4 for a description and picture of $\mathrm{P}-1$.

\subsubsection{Task 6 Results and Discussion}

A number of P-1 operating campaigns were carried out during this reporting period. The longest of which were a 60 -hour test and a 100-hour test. This testing was conducted with a low number of OTM elements installed in the reactor and utilized inert fill rather than active reforming catalyst. Since the goal was to achieve steady state operation, effort was made to identify and eliminate causes of plant shutdowns and unacceptable process deviations. The work also included the identification and automation of operating protocols. Both the plant improvements and operating protocols were necessary to ensure the survival of the ceramic OTM elements.

The following graph, Figure 15, illustrates the performance of the temperature ramping feature that was added as part of the automated operating protocol. 


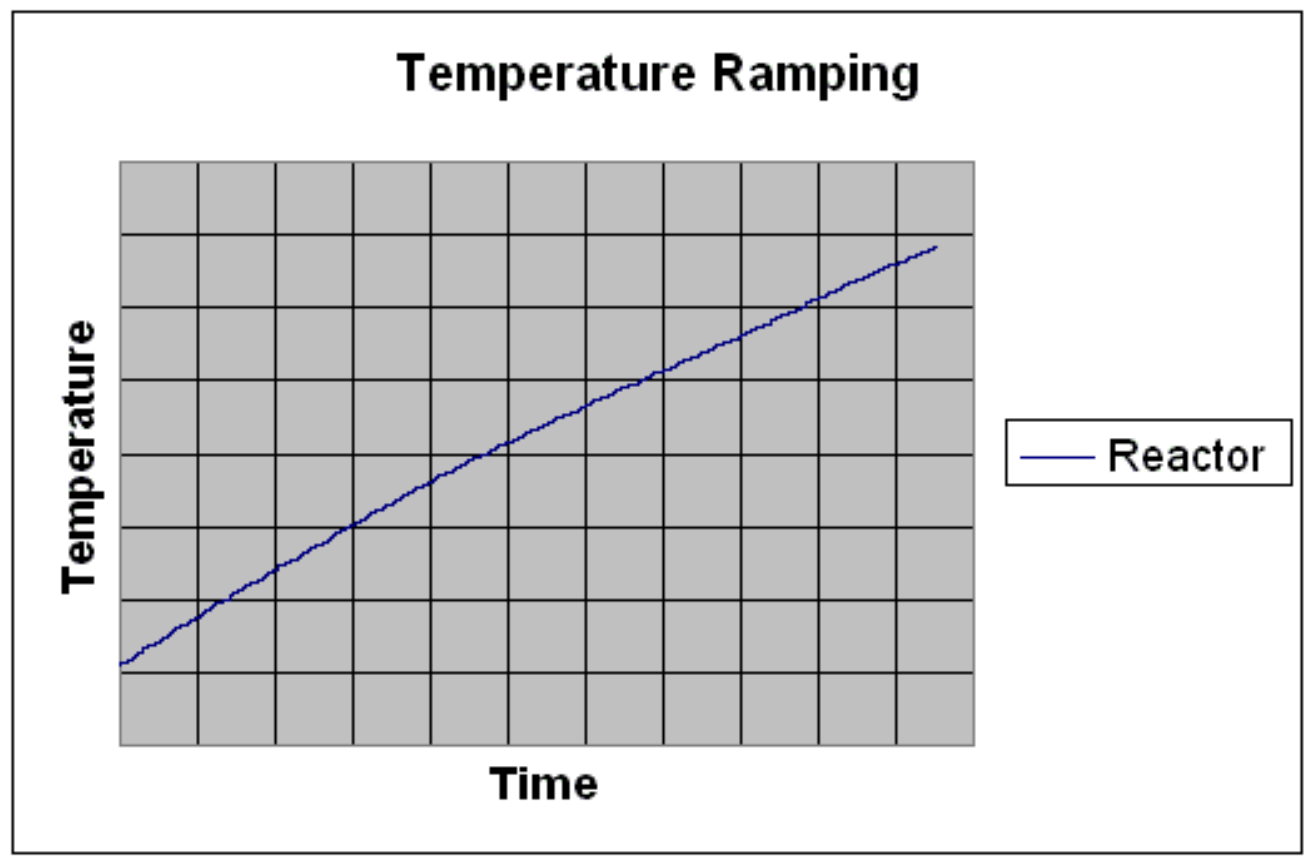

Figure 15. Reactor Temperature Ramp

\subsubsection{Task 6 Conclusions}

After the implementation of a number of equipment and control system modifications for enhanced system operability and reliability, steady state operation of P1 was achieved using $1^{\text {st }}$ generation materials, elements and inert catalyst. Although more robust OTM elements would facilitate testing progress, P1 and the current OTM elements have been proven ready to begin the next stage of higher tube count testing.

\subsection{Task 7: P-2 Build and Operation}

\subsubsection{Goal - Task 7}

The purpose of the P-2 pilot plant is to demonstrate the commercial (technical and economic) feasibility of the OTM syngas technology. P-2 will be sized to demonstrate key scale-up risks and economic variables.

\subsubsection{Milestones - Task 7}

This budget period: None

Next budget period: 2Q02-- Submit NEPA documentation for P-2; 3Q02--preliminary design and cost estimate for P-2 completed.

\subsection{Task 8: Fuel and Engine Testing}

A matrix of UCTF will be prepared for testing at each engine (International Truck and Engine) or fuel cell developer (Nuvera Fuel Cells). The fuel matrix will include a base stock of syngas derived Fischer Tropsch liquids and will study the addition of advanced oxygenates supplied by BP. The result of the study will be the impact of fuel properties on emissions and engine (or fuel cell) system performance. 


\subsubsection{Diesel Engines and Exhaust Treatment}

\subsubsection{Goal - Diesel Engines and Exhaust Treatment}

The goal of this task is to understand the relationship between ultra-clean fuel properties and their impact on the emissions and performance of an advanced CIDI and exhaust treatment system under development by International Truck and Engine.

\subsubsection{Milestones - Diesel Engines and Exhaust Treatment}

This budget period: 2Q01--define test matrix, order long lead fuels, kick-off program Status--Fuels ordered and received, test matrix agreed, program started.

\subsubsection{Experimental - Diesel Engines and Exhaust Treatment}

A two-tier test program shall examine the effect of fuel composition (sulfur, oxygenates, hydrocarbon-type conventional diesel, or non-aromatic FT diesel) on engine performance and engine emissions. The first tier will be single cylinder tests with five fuel blends that will focus on in-cylinder emissions reduction. The second tier shall test various fuel compositions in an advanced multi-cylinder CIDI test engine with various after-treatment technologies. The single cylinder engine specifications are shown in Table 3.

Table 3. Single Cylinder Engine Specifications

\begin{tabular}{|l|l|}
\hline Engine & single cylinder engine \\
\hline Bore $\mathrm{x}$ Stroke & $95 \times 105 \mathrm{~mm}$ \\
\hline Compression Ratio & 18.5 \\
\hline Displacement & $0.744 \mathrm{~L} /$ cylinder \\
\hline Injector & $\mathrm{G} 2 \mathrm{SV} 2.5$ \\
\hline Injector Nozzle & $6 \times 154 \times 525$ \\
\hline Valve Train & 4 valves per cylinder \\
\hline
\end{tabular}

Pictures of International Truck and Engine Corporation's Facility are attached in Appendix 7 page A-8.

\subsubsection{Diesel Engines and Exhaust Treatment Results and Discussion}

Single cylinder engine test have just been begun; no results are available yet.

\subsubsection{Nuvera Fuel Cells}

\subsubsection{Goal - Nuvera Fuel Cells}

The goal is to understand effect of UCTF on this fuel cell system and possibly reduce emissions on a per mile basis.

\subsubsection{Milestones - Nuvera Fuel Cells}

This budget period: 2Q01--Order long lead items (fuels for testing); 3Q01--kick-off meetings Nuvera; Full power train tests on two fuels at Nuvera Status--Fuels ordered and received, test matrix agreed, program underway Next budget period: 4Q01--Complete burner studies 


\subsubsection{Experimental - Nuvera Fuel Cells}

A schematic of the experimental setup is shown below in Figure 16. Pictures of the MPR Facility are attached in Appendix 6 page A-7.

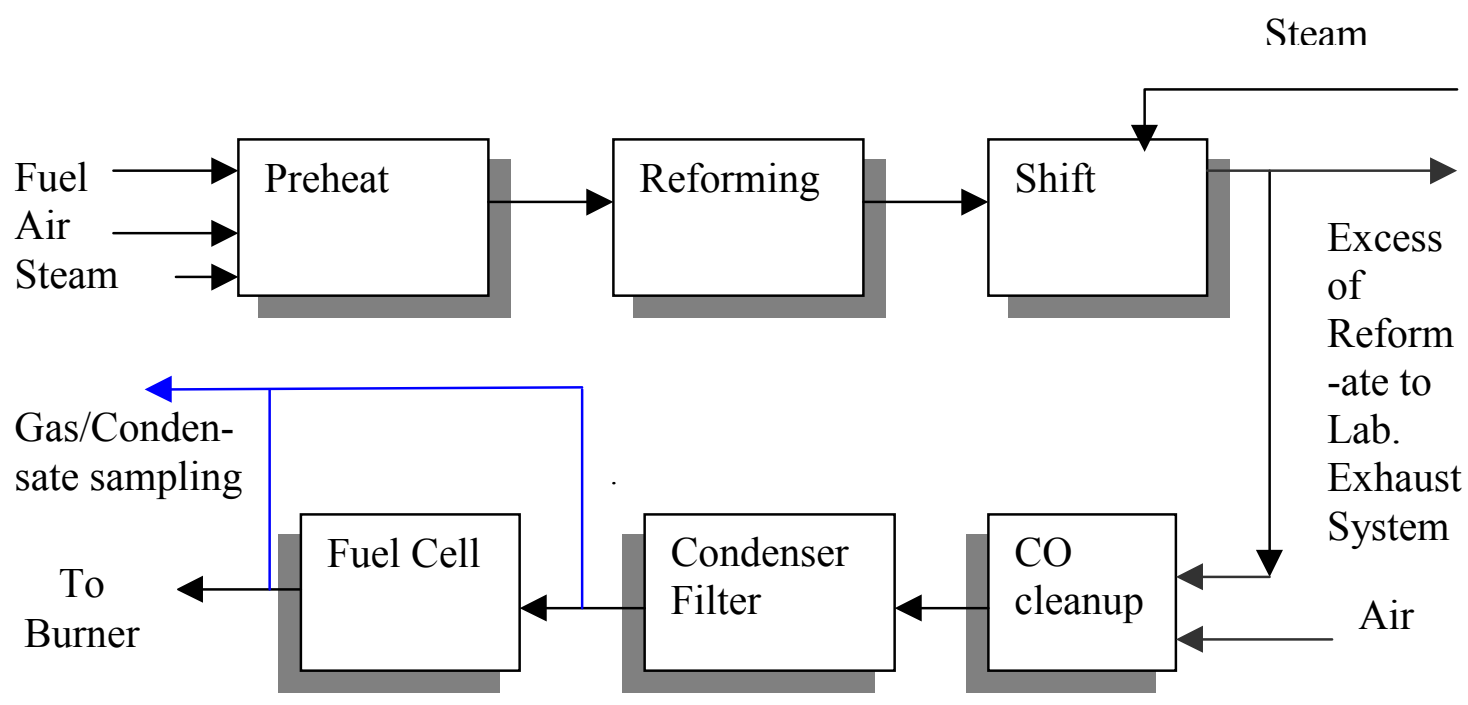

Figure 16. Nuvera Fuel Cells Modular Pressurized Reactor Schematic

The autothermal reforming of the specified fuels will be conducted in the MPR (Modular Pressurized Reactor) facility. The MPR test matrix is shown in Table 4.

Table 4. MPR Test Matrix

\begin{tabular}{|l|l|l|}
\hline FUEL COMPOSITION & $\begin{array}{l}\text { Cal. Phase 2 Gasoline, 35 } \\
\text { ppm sulfur }\end{array}$ & FT/Naphtha blend 1 \\
\hline Air/Fuel Stoichiometry, $\varphi$ & 3.75 & 3.75 \\
\hline $\begin{array}{l}\text { Water/fuel stoichiometry, } \\
\text { Steam/Carbon }\end{array}$ & 3.4 & 3.4 \\
\hline Power/throughput, KWth & 60 & 60 \\
\hline
\end{tabular}

The fuel cell stack testing matrix is described in Table 5.

Table 5. Fuel Cell Test Matrix

\begin{tabular}{|l|l|}
\hline Stack temperature, $\mathrm{C}$ & 70 \\
\hline Pressure, psig & 20 \\
\hline Cathode humidification, $\%$ & $80-100$ at $65^{\circ} \mathrm{C}$ \\
\hline Cathode stoichiometry & 2 \\
\hline Anode stoichiometry & $1.5-2$ \\
\hline
\end{tabular}

The following data will be recorded during experiment: 
- $\quad$ all operating conditions specified above;

- $\quad$ the dry bulk composition of the reformate at the exit of MPR clean-up section (vol. \% of $\mathrm{H} 2, \mathrm{CO} 2, \mathrm{CH} 4, \mathrm{~N} 2$ )

- $\quad$ the dry bulk composition of the Fuel Cell anode exhaust (vol. \% of H2, CO2, $\mathrm{CH} 4, \mathrm{~N} 2)$

- $\quad$ the PPM levels of other components, if any, in the reformate stream at the exit of MPR clean-up section

- $\quad$ the PPM levels of other components, if any, in the Fuel Cell Anode Exhaust

\subsubsection{Results and Discussion - Nuvera Fuel Cells}

Two fuels were selected for the first series of tests on the MPR facility. One fuel is a CARB gasoline obtained from California. This commercially available fuel meets the current strict emission standards of the state of California. The second fuel is a Fischer Tropsch naphtha obtained from the Sasol-Chevron joint venture. This is a highly paraffin fuel with essentially no sulfur, nitrogen or aromatics.

Both fuels will be compared in the MPR as described above.

\subsection{Task 9: Market Study}

\subsubsection{Goal - Task 9}

The goal of this task is to understand marketing and commercialization hurdles and to develop plans to bring the ultra-clean fuel system to market.

\subsubsection{Milestones - Task 9}

Note--this study does not begin until Year 3, so there are no near term milestones.

\subsection{Task 10: Program Management}

\subsubsection{Goal - Task 10}

The Recipient shall provide technical leadership and management direction to ensure that the program delivers its goals on time, within budget, and in a safe and environmentally acceptable manner. Good communications with DOE, participants, and sub-contractors will be maintained.

\subsubsection{Milestones - Task 10}

A detailed briefing shall be presented within sixty (60) days after agreement award. The briefings shall be given by the Recipient to explain the plans, progress, and results of the project effort, both technical and administrative.

Status: Accomplished--detailed briefing was provided to the DOE on July 25, 2001. Enlist subcontractors and initiate work plans within 90 days of award.

Status: Accomplished--subcontracts were let and work initiated by mid August.

\subsubsection{Discussion - Task 10}

The program award was finalized on May 21, 2001. In anticipation of award closure, work at Praxair and BP had proceeded since January 1, 2001 and costs were accrued at 
their own risk. Other subcontractors were not enlisted until after the Praxair/DOE contract was finalized; however, arrangements were made to procure long lead fuel samples for Task 8. This included drum quantities of syngas derived Fischer Tropsch naphtha and diesel fuels obtained from the Sasol-Chevron joint venture. The fuels were delivered in time to avoid delays in the program.

Total program costs to date are tracking close to budget.

Technical progress is mostly on track with the exception of selecting a new lead commercial material. This is a critical path item, which can control advancements in other tasks, especially Task 3, Tube Manufacturing. Nonetheless good progress is being made with the current lead material (LCM1) which is sufficiently robust to enable progress in reactor and process development (Task 4) and tube manufacturing (Task 3 ).

\subsection{Budget Period 1 Conclusions}

Significant progress has been made in the OTM syngas tasks of this project during Budget Period 1. Due to subcontract negotiations and modifications in scope of work, the fuels and engine development (Task 8) work was initiated in August 2001.

In Materials Development work (Task 1), it was determined that the benchmark material, LCM1, exceeds the commercial oxygen flux target and is sufficiently robust for process development and pilot plant activities. In addition to LCM1, two new materials were completely characterized and five other materials are in various stages of fabrication or testing. All of these materials satisfy the oxygen flux requirement; and several have demonstrated superior mechanical properties. Work will continue to develop and select second-generation material(s) with superior mechanical properties that can withstand long-term commercial life targets.

Fabrication techniques to commercially manufacture composite elements (Task 2) while optimizing strength and oxygen flux were investigated this Budget Period. Three manufacturing techniques for making robust composite tubes have proven technically feasible based on the capability to make leak free composite elements with uniform geometry. Each manufacturing technique will be studied in detail next Budget Period. Selection of the lead manufacturing process for composite elements has been postponed until the next Budget Period, pending selection of commercial material(s) in Task 1.

Scale-up of manufacturing techniques for producing both small-scale and large-scale ceramic OTM elements (Task 3) was conducted this Budget Period. LCM1 and LCM2 composite elements for P-0 tests and tubes up to $140 \mathrm{~cm}$ in length for LTT and P-1 pilot plant tests were fabricated and were tested. These elements exhibited excellent straightness and roundness and incorporated a special open end for sealing. Final selection of the commercial manufacturing technique will be determined in the next Budget Period pending selection of the commercial material(s). 
Significant progress has been made in Task 4 (Reactor Design and Process Optimization). P-0 tests in six reactors evaluate alternative element architectures and materials, as well as studying effect of process conditions and tube morphology on temperature profiles and element performance.

Construction of a new pilot plant, the Long Tube Tester (LTT), was completed at the end of June. This unit is capable of testing OTM elements up to six feet in length with a variety of process gases and flow configurations at target temperatures and pressures. Commissioning of all systems is complete and the unit is in start-up mode.

The P-1 Pilot Plant (Task 6) achieved a milestone operation of 100 hours, including successful start-up and shutdown without a tube failure. This run utilized two OTM elements. The unit is now configured with $15 \mathrm{OTM}$ elements, $140 \mathrm{~cm}$ length, and is undergoing start-up.

Two seal design types are being developed. These seals hold the ceramic elements in the reactors and are in use in all of the bench scale and pilot plant units. Both types can be thermally and pressure cycled and can accommodate the thermal and compositional expansion characteristics of the OTM elements.

In modeling, a CFD code has been developed that includes hydrodynamic descriptions of the reactor internals, and kinetic descriptions for both oxygen diffusion through the ceramic OTM and heterogeneous catalysis of steam methane reforming and water gas shift reactions. Fluid flow, heat and mass transfer and reaction kinetics are coupled to give an accurate representation of the reactor performance. The model is being validated against P-0, LTT and P-1 results. These models, plus simpler codes are being used to evaluate alternative reactor designs and process configurations.

Development of tailored catalysts (Task 5) suitable for the unique operating environment of an OTM process reactor has successfully yielded three candidates, all of which can satisfy activity targets. At least one catalyst systemqualifies for the P-1 application, meeting the milestone target for this Budget Period. Work continues to optimize the performance, cost and life characteristics of a commercial catalyst system. A detailed model based on intrinsic kinetic experiments has been completed for one of the catalyst candidates. This model is incorporated in the reactor CFD code.

Fuels testing and engine development work (Task 8) are now underway at Nuvera Fuel Cells and International Truck and Engine. Long lead-time for fuel requirements were anticipated and fuel orders were placed to prevent delays in Task 8. Experimental plans have been finalized and Fischer Tropsch-based fuels (an FTL naphtha for Nuvera and a FTL diesel for International) have been delivered to both sites.

Program Management (Task 10) has been successful in kicking off all sub-contractor work in a timely fashion after the DOE /Praxair contract was signed on May 21, 2001. Subcontracts with BP Amoco, Nuvera Fuel Cells and International Truck and Engine were executed in August 2001 and work is underway at all sites. A detailed briefing was 
provided to the DOE during the program kick-off meeting held at the DOE NETL Morgantown, WV site on July 25, 2001.

\subsection{References}

1. G. Majkic, L. Wheeler, K. Salma, Acta. Mater. 48 (2000) p.1907-1917.

2. Private Communiqué, "Creep Results for LCM materials", T. Stephens, April, 2001

3. Private Communiqué, "Sintering Study of LCM3, LCM5 and LCM6", K. Kleveland, March, 2001

4. Private Communiqué, "Properties of Different Membrane and Substrate Materials, S Aasland and K. Kleveland, April 2001

5. Private Communiqué, "Properties of LCM3 compared to LCM1", J. Sirman, September 2001

6. Private Communiqué, "Vickers Indentation Hardness and Fracture Toughness of LCM1 and Other Materials", B. Krogh and K. Kleveland, April, 2001 


\section{Appendix \\ for Topical Report}

Development of OTM Syngas Process and Testing of Syngas-Derived Ultra-clean Fuels in Diesel Engines and Fuel Cells

Budget Period 1

October 2001 


\section{Appendix 1. Disk Reactor}

Permeation cells for measuring the oxygen flux of discs of OTM materials is in place at Praxair and BP. The permeation cell has an air feed stream passing over the surface of the membrane where oxygen is removed from the gas stream and incorporated into the OTM sample. On the other side of the disk a fuel, gas purge stream is passed over the membrane surface and oxygen is extracted from the OTM material at atmospheric pressure. The oxygen flux can be calculated by measuring the fraction of oxygen in the depleted air stream and the compositional changes in the fuel gas stream. Leaks are detected by monitoring nitrogen concentrations in the fuel purge stream. The sample is contained in a furnace allowing temperature dependence measurements. A view of a permeation cell is shown below.

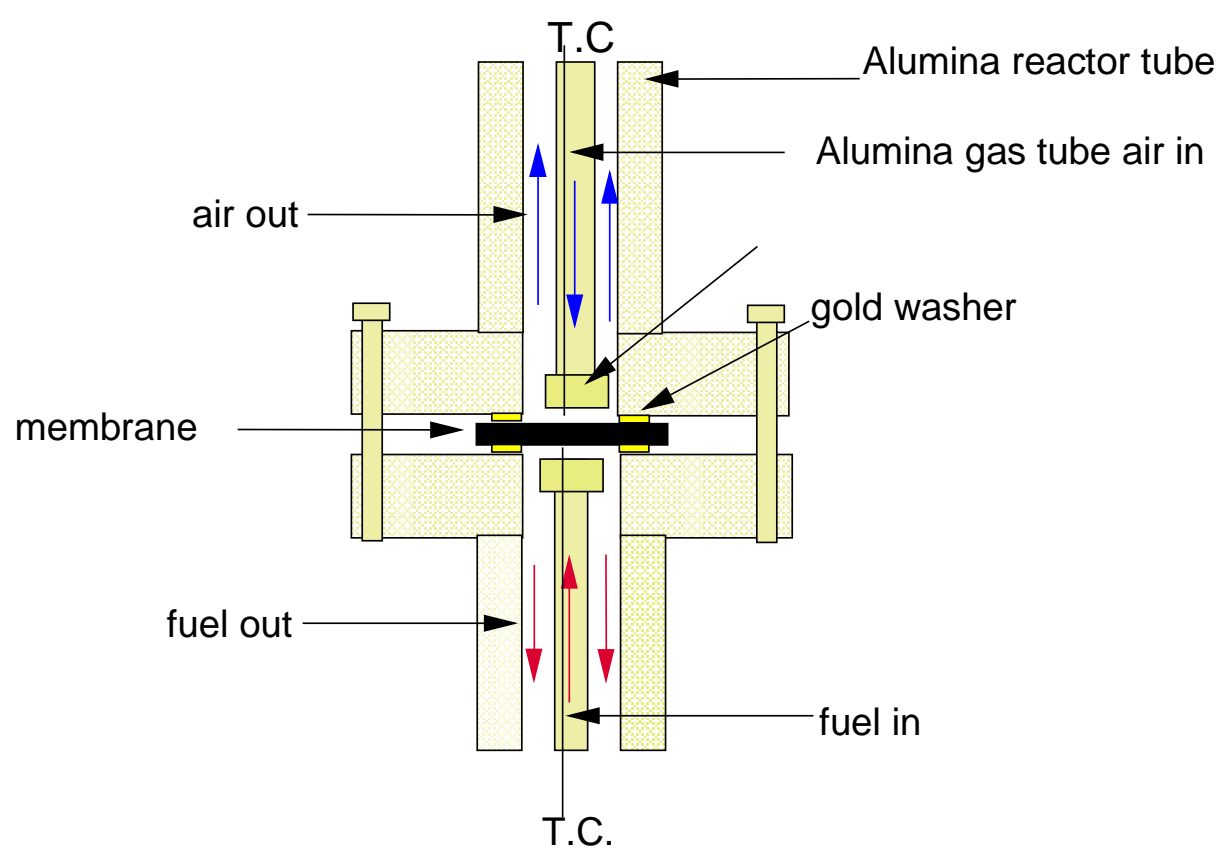

Disk Reactor Permeation Cell 


\section{Appendix 2. P-0 Reactor}

Six P-0 reactors are available for testing small OTM tubes. Each P-0 reactor includes the following: a three-zone furnace is used to heat the OTM to the operating temperature, between 800 and $1050^{\circ} \mathrm{C}$.; a gas manifold that delivers oxygen, nitrogen, air, and mixtures thereof to the OTM, a saturator that provides steam for the process gas feed and backpressure regulators to control the pressure both at the air side and the fuel product side of the membrane. A gas chromatograph is used to measure gas compositions and a paramagnetic oxygen analyzer is used to determine the level of oxygen depletion from the air stream. Numerous automatic shutoffs exist so that the reactor can be operated safely. A view of a P-0 reactor is shown below:
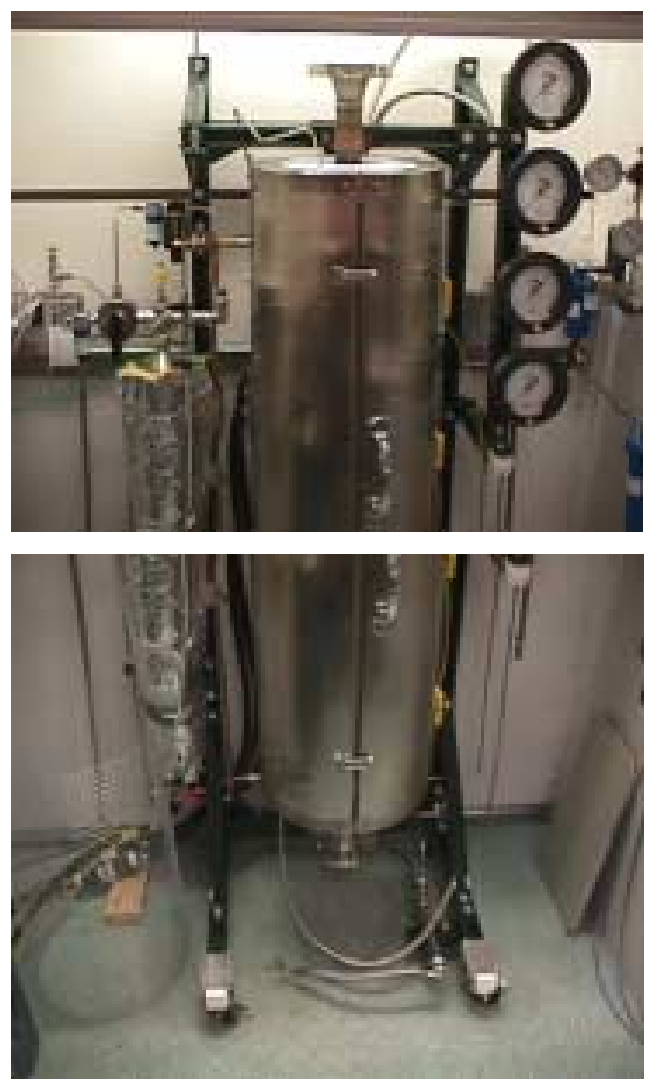

\section{P-0 Reactor}

The flux of oxygen through the OTM tube, $J_{O_{o}}$, is determined using Equation [A.1]:

$$
J_{O_{2}}=\frac{y_{O_{2}} F_{\text {purge }}}{A_{\text {OTM }}} \quad \text { Equation [A.1] }
$$

where:

$J_{O_{2}}=$ Average oxygen flux $\left(\mathrm{sccm} / \mathrm{cm}^{2}\right)$

$y_{O_{2}}=$ Oxygen mole fraction in the purge gas as measured by the oxygen analyzer

$F_{\text {purge }}=$ Volumetric flow rate of the purge gas as measured by the Flowmeter

$A_{\text {OTM }}=$ OTM Area $\left(\mathrm{cm}^{2}\right)$ 


\section{Appendix 3. Long Tube Tester}

The Long Tube Tester (LTT) is designed to test a commercial scale ceramic oxygen transport membrane (OTM) in the production of synthesis gas using methane, air and steam. The LTT consists of an electrically heated reactor, a feed heater, discharge coolers and various controls, all of which are located within a ventilated enclosure. A view of the LTT is shown below with the analytical equipment and control panels visible on the side of the LTT enclosure.

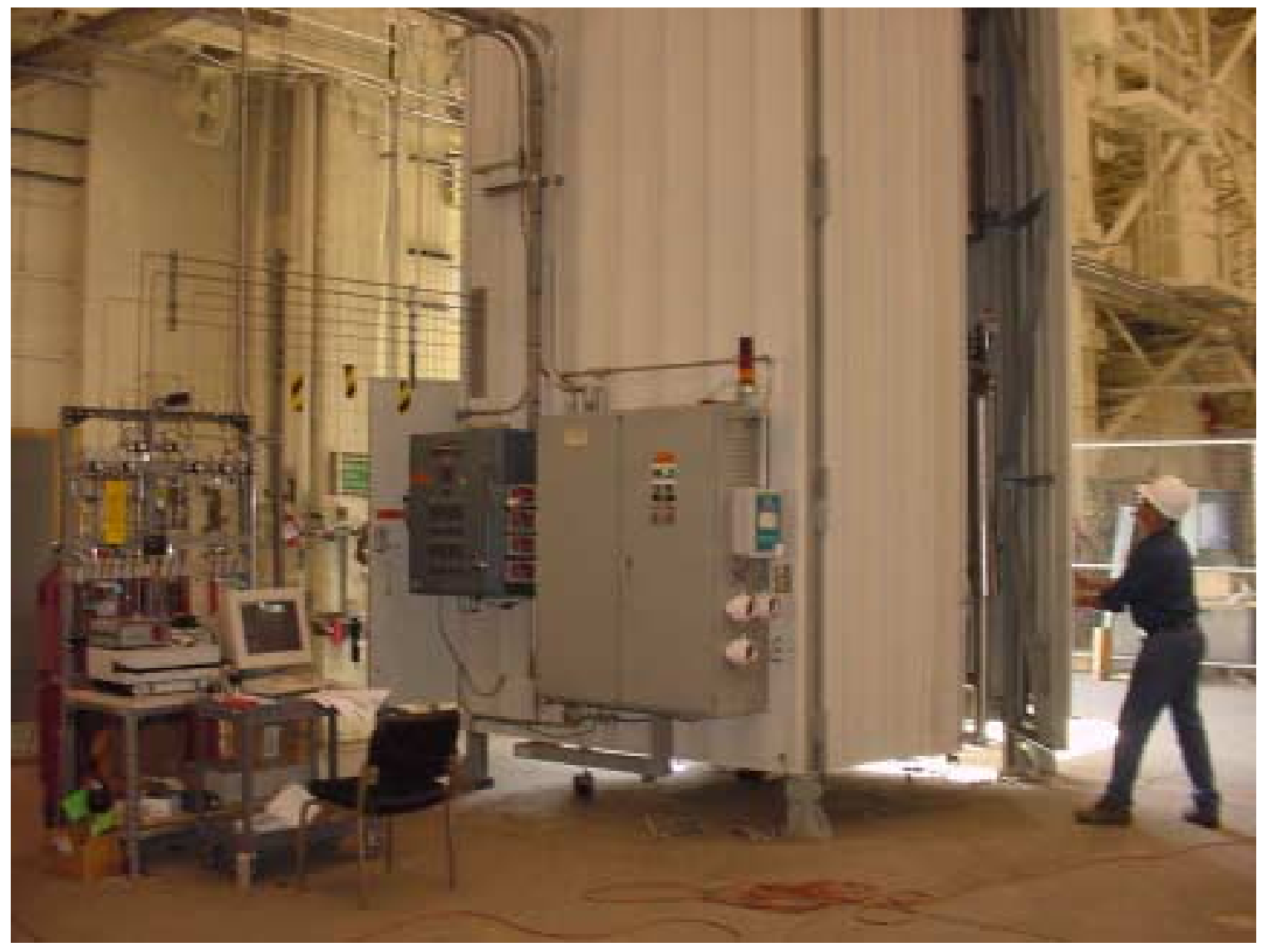

Long Tube Tester Pilot Plant Facility 


\section{Appendix 4. P-1 Pilot Plant}

The P-1 Pilot Plant (P-1) is designed to demonstrate the technical feasibility of the OTM synthesis gas generation technology under steady state and transient conditions using commercial scale OTMs. P-1 consists of a multi-tube reactor, feed heaters, discharge coolers and various controls, all of which are located within a ventilated enclosure. A view of the P-1 reactor is shown below with a portion of the reactor vessel visible below the enclosure.

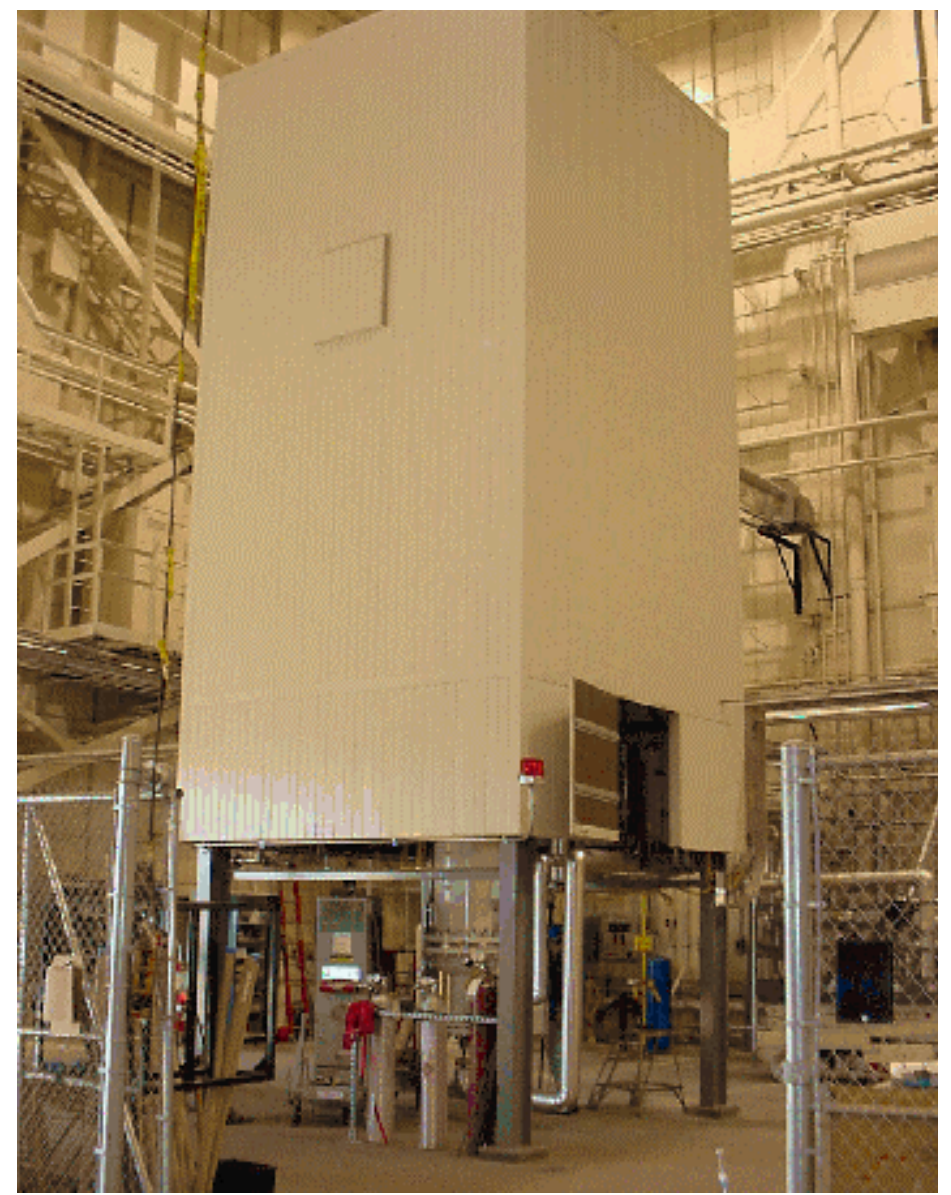

P-1 Pilot Plant 


\section{Appendix 5. Element Manufacturing Facilities}

5.a Green Forming Facilities

\section{Iso-static pressing - Indianapolis}
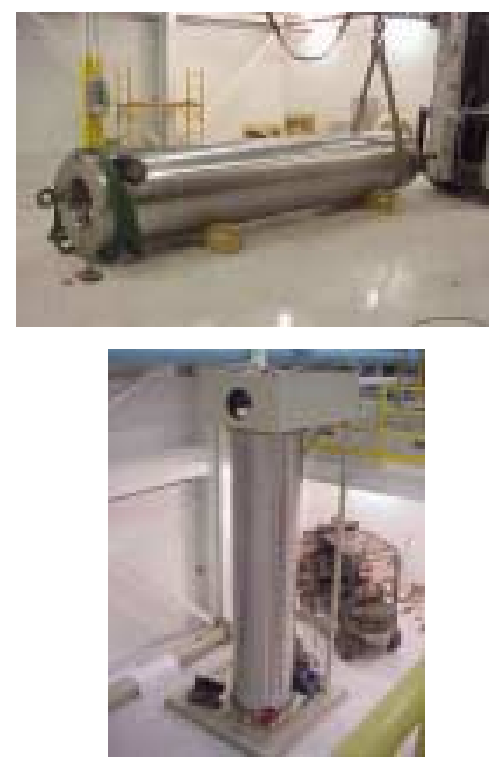
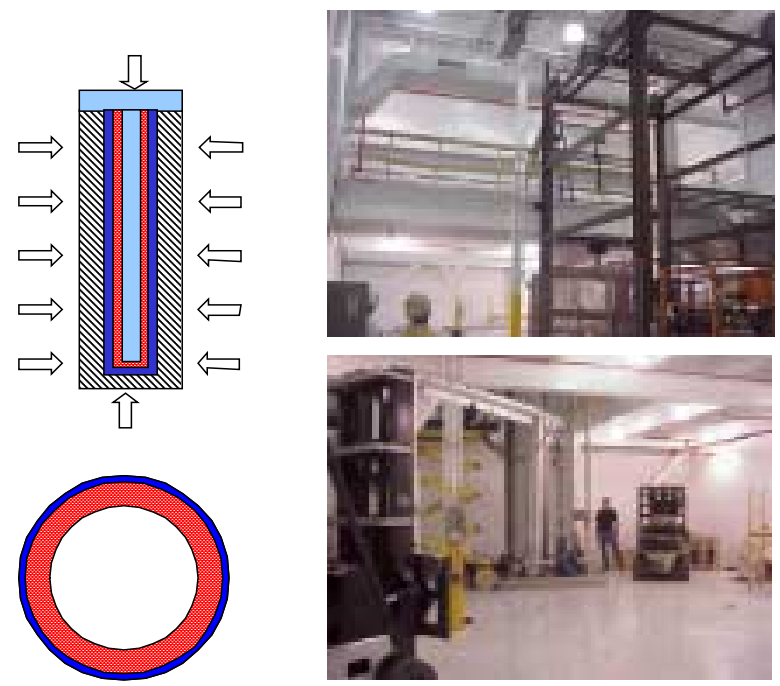

Isostatic Press

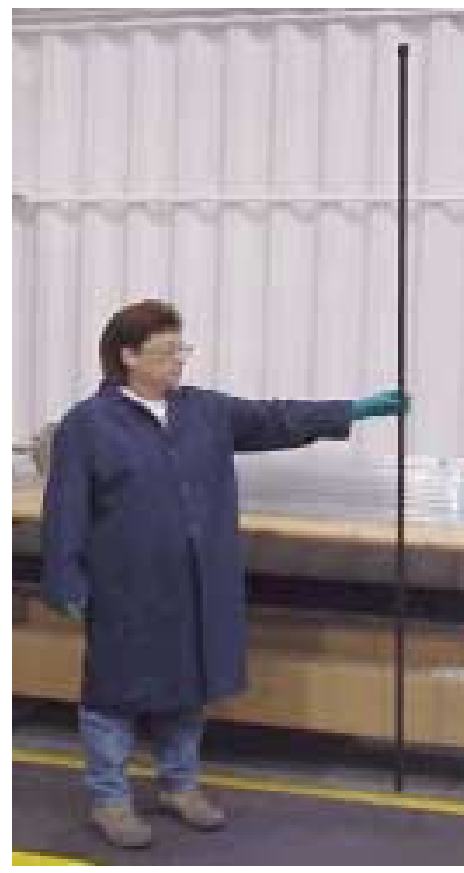

Example of long Green Tube [225cm] 


\section{5.b Sintering Facilities}

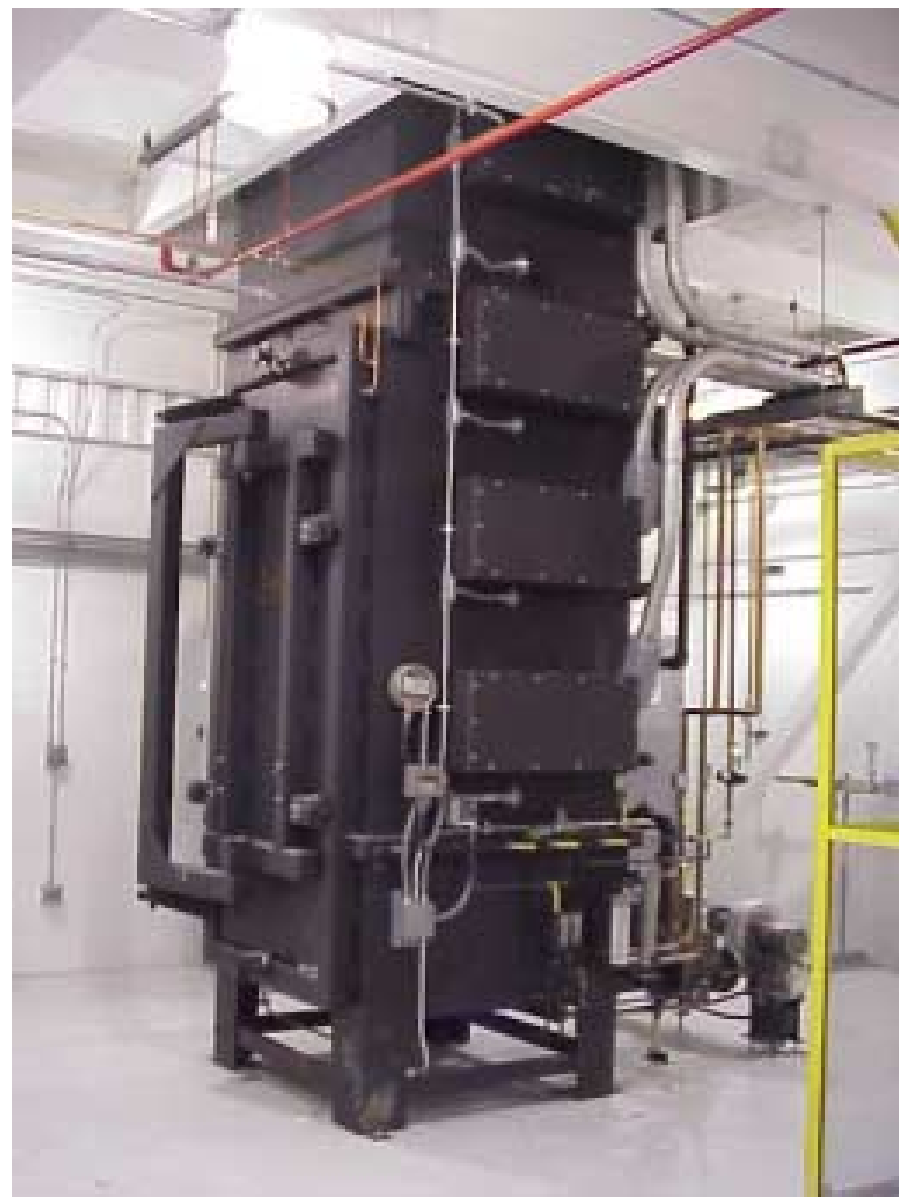

Sintering Furnace 


\section{Appendix 6. Photographs of the Nuvera MPR Facility}

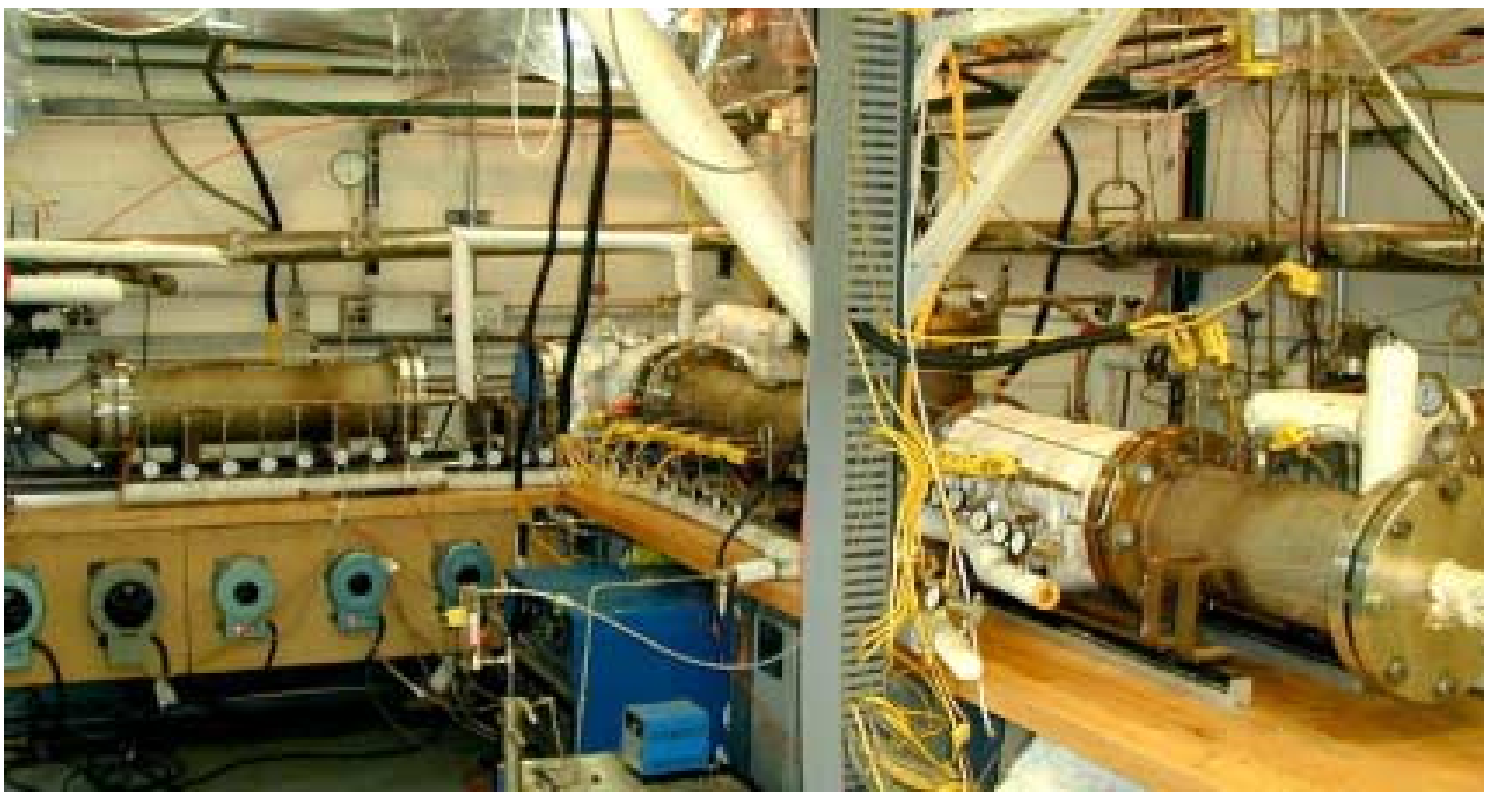

Nuvera MPR Facility: Pre-heat, Reforming, Shift and CO Cleanup Modules

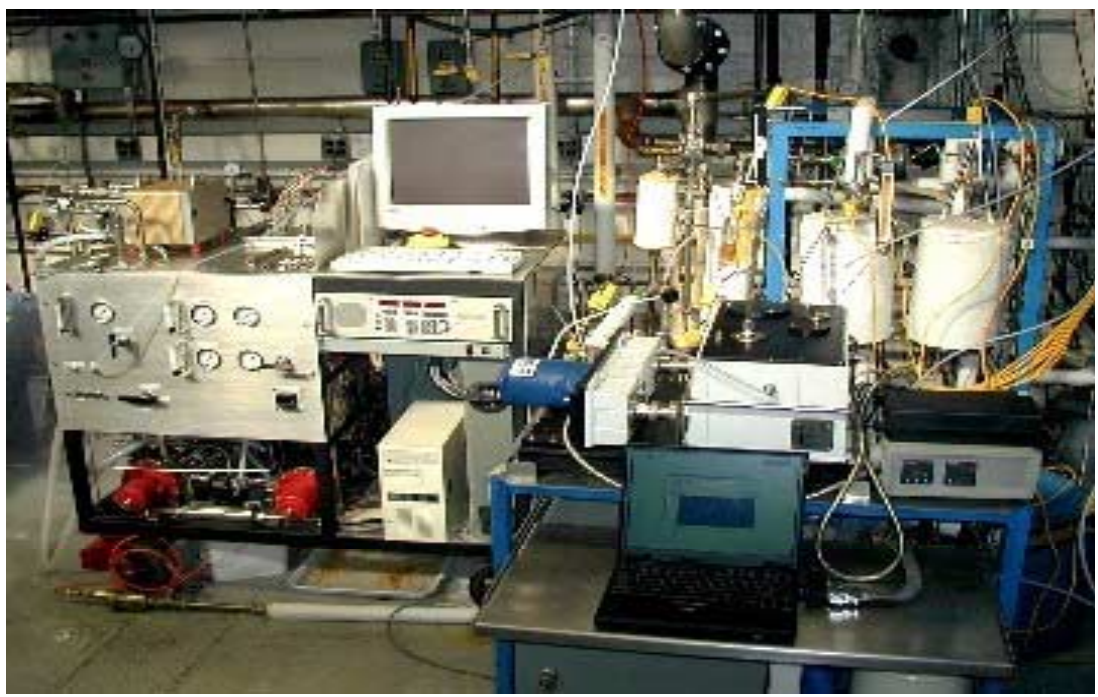

Nuvera MPR Facility: Fuel Cell Stack, Instrumentation and Controls 


\section{Appendix 7. Photographs of the International Truck and} Engine Facility

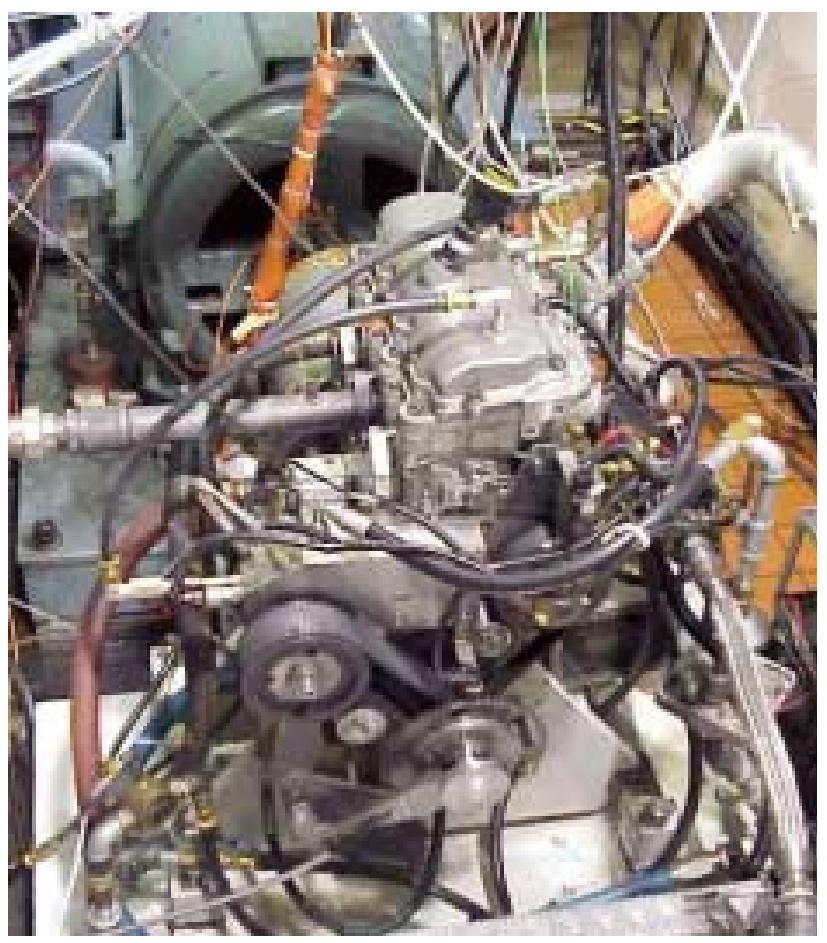

International's CIDI Engine

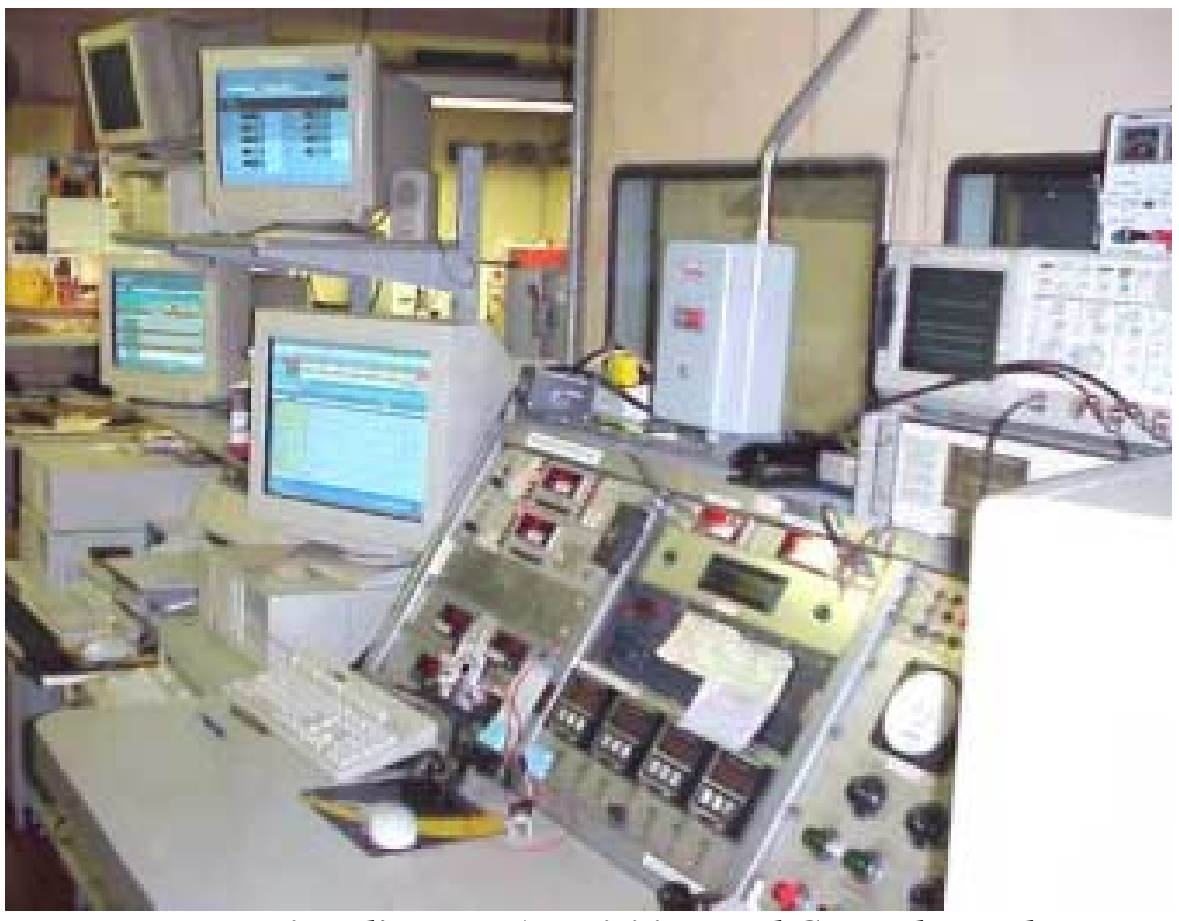

International's Data Acquisition and Control Panel 